\title{
A survey of ELF and VLF research on lightning-ionosphere interactions and causative discharges
}

\author{
U. S. Inan, ${ }^{1,2}$ S. A. Cummer, ${ }^{3}$ and R. A. Marshall ${ }^{1,4}$ \\ Received 14 August 2009; revised 20 November 2009; accepted 6 January 2010; published 18 June 2010.
}

[1] Extremely low frequency (ELF) and very low frequency (VLF) observations have formed the cornerstone of measurement and interpretation of effects of lightning discharges on the overlying upper atmospheric regions, as well as near-Earth space. ELF $(0.3-3 \mathrm{kHz})$ and VLF $(3-30 \mathrm{kHz})$ wave energy released by lightning discharges is often the agent of modification of the lower ionospheric medium that results in the conductivity changes and the excitation of optical emissions that constitute transient luminous events (TLEs). In addition, the resultant ionospheric changes are best (and often uniquely) observable as perturbations of subionospherically propagating VLF signals. In fact, some of the earliest evidence for direct disturbances of the lower ionosphere in association with lightning discharges was obtained in the course of the study of such VLF perturbations. Measurements of the detailed ELF and VLF waveforms of parent lightning discharges that produce TLEs and terrestrial gamma ray flashes (TGFs) have also been very fruitful, often revealing properties of such discharges that maximize ionospheric effects, such as generation of intense electromagnetic pulses (EMPs) or removal of large quantities of charge. In this paper, we provide a review of the development of ELF and VLF measurements, both from a historical point of view and from the point of view of their relationship to optical and other observations of ionospheric effects of lightning discharges.

Citation: Inan, U. S., S. A. Cummer, and R. A. Marshall (2010), A survey of ELF and VLF research on lightning-ionosphere interactions and causative discharges, J. Geophys. Res., 115, A00E36, doi:10.1029/2009JA014775.

\section{Introduction}

[2] The $D$ region ionosphere spans the altitude range between 60 and $100 \mathrm{~km}$, a region often dubbed the "ignorosphere" due to the difficulty of systematic measurements [Sechrist, 1974]; the altitude range is too high for balloons, and too low for in situ satellite measurements. Typical methods for studying the $D$ region include in situ rocket measurements, which are necessarily transient; VHF radar measurements of the mesosphere-lower thermosphere (MLT) region; and long-wave (i.e., VLF and LF) probing. The VLF technique for probing the $D$ region takes advantage of the fact that waves in the VLF frequency range $(3-30 \mathrm{kHz})$ reflect from the lower ionosphere at an altitude of $\sim 60 \mathrm{~km}$ in the daytime and $\sim 85 \mathrm{~km}$ at night, and the received signal inherently contains information about that region of the ionosphere and its variability. Furthermore, these frequencies propagate over long dis-

\footnotetext{
${ }^{1}$ STAR Laboratory, Stanford University, Stanford, California, USA. ${ }^{2}$ Koç University, Istanbul, Turkey.

${ }^{3}$ Electrical and Computer Engineering Department, Duke University, Durham, North Carolina, USA.

${ }^{4}$ Center for Space Physics, Boston University, Boston, Massachusetts, USA.

Copyright 2010 by the American Geophysical Union. 0148-0227/10/2009JA014775
}

tances (tens of megameters) with low loss ( $\sim 2 \mathrm{~dB}$ per $\mathrm{Mm})$ in the Earth-ionosphere waveguide, thanks to the $\sim 90 \mathrm{~km}$ thickness of the waveguide at night.

[3] The sources of VLF energy of interest to us in this paper are twofold: man-made, ground-based VLF transmitters, which typically operate from as low as $12 \mathrm{kHz}$ (Russian alpha transmitters) to as high as $40.75 \mathrm{kHz}$ (the NAU transmitter in Puerto Rico); and lightning, whose radio energy spans up to $10 \mathrm{GHz}$, but peaks in the $5-10 \mathrm{kHz}$ range [Rakov and Uman, 2003, p. 6]. The peak radiation component of the lightning electric field at ionospheric altitudes can reach $15 \mathrm{~V} / \mathrm{m}$ or higher [Lu, 2006; Marshall et al., 2010], exceeding the thresholds of ionization and optical emissions from atmospheric constituents, and thus causing direct $D$ region ionospheric modification. VLF transmitters are not powerful enough to cause ionization in the $D$ region, but they can heat the ionosphere enough to observably modify its conductivity [Rodriguez et al., 1994]. Furthermore, these VLF transmitter signals, when observed at long range, can be used to "probe" the $D$ region ionosphere, providing an important measurement technique of localized $D$ region disturbances.

[4] In this review, we discuss the uses of ELF and VLF observations for studying the $D$ region ionosphere and provide a survey of the literature in this area. In sections 2 and 3 we provide an introduction to the VLF probing technique, and its use in studying lightning-induced electron precipitation (LEP) events and "early" perturbations. Section 4 deals with 

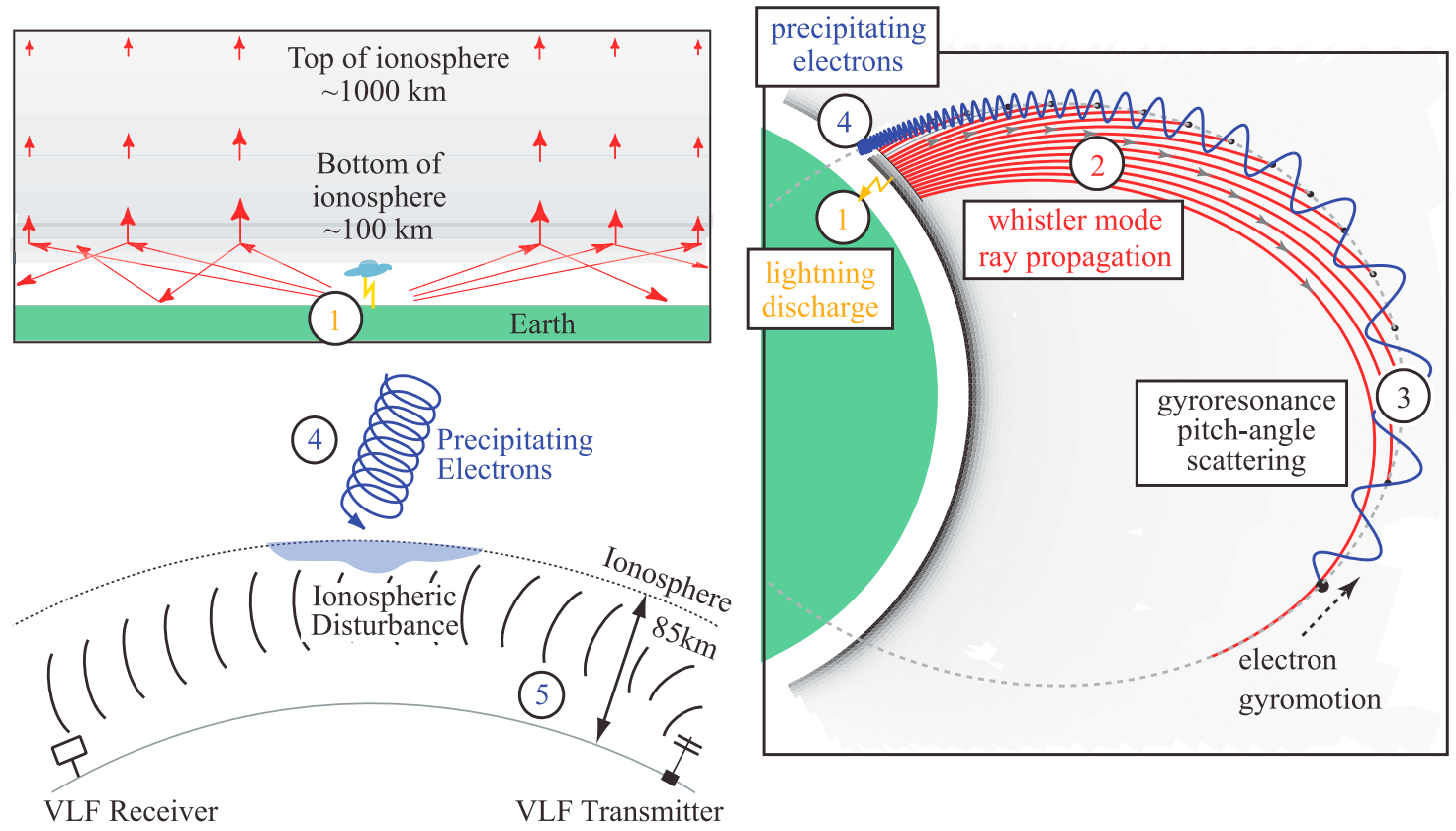

Figure 1. Physical mechanism of LEP. (1) Lightning injects VLF energy into the Earth-ionosphere waveguide and into the magnetosphere. (2) VLF energy propagates as whistler mode waves in the plasmasphere. (3) Whistler waves interact in gyroresonance with relativistic radiation belt electrons, scattering them in energy and pitch angle. (4) Relativistic electrons scattered into the loss cone precipitate in the upper atmosphere through collisions with neutrals. (5) Secondary ionization is detected by subionospheric VLF probing techniques. Adapted from Lauben et al. [2001].

the interaction between the lightning EMP and the ionosphere and the resulting density changes and elves. In section 5 we discuss the use of ELF and VLF signatures of lightning that produce sprites, halos, and elves, while section 6 discusses VLF "sferic bursts" and their relationship with in-cloud (IC) lightning discharges. Finally, section 7 discusses the relationship between VLF measurements and gamma ray events, in particular the recently discovered terrestrial gamma ray flashes (TGFs).

\section{Lightning-Induced Electron Precipitation}

[5] The basic mechanism for lightning-induced electron precipitation (LEP) events is illustrated in Figure 1. The electromagnetic pulse from lightning (1) propagates primarily in the Earth-ionosphere waveguide, but a small fraction of its energy penetrates through the ionosphere and into the magnetosphere, where it propagates (2) as a whistler mode wave [Helliwell, 1965]. This whistler energy propagates at $\sim 0.1 c$ to $0.01 c$ either obliquely in the plasmasphere (as shown), or along field-aligned density enhancements known as ducts. In the equatorial region, the whistler energy in the 1$10 \mathrm{kHz}$ range interacts with radiation belt electrons of $\sim 100$ $300 \mathrm{keV}$ in cyclotron resonance and may cause pitch angle and energy scattering (3). Electrons scattered from their trapped orbits into the bounce loss cone precipitate (4) in the upper atmosphere (at $60-120 \mathrm{~km}$ ) due to collisions with neutral molecules. This burst of precipitation causes an ionospheric disturbance, i.e., an electron density enhancement, which can be detected via phase and/or amplitude changes on subionospheric VLF transmitter signals (5), or by in situ rocket (200-300 km altitude) or satellite $(300-700 \mathrm{~km}$ altitude) measurements.

[6] Whether the whistler waves propagate obliquely (nonducted, i.e., waves which do not propagate along magnetic field lines) or ducted (along the field lines, guided by field-aligned density depletions) can be determined based on the location of the precipitation region: for oblique (nonducted) whistlers, this precipitation occurs over a wide region centered poleward of the lightning discharge, as shown in Figure 1, while the location of ducted precipitation is more localized and determined by the location of the "duct," which may or may not be directly above the lightning discharge.

[7] LEP events have been observed on transmitter signals at frequencies as low as $2.45 \mathrm{kHz}$ (at Siple Station, Antarctica [Carpenter et al., 1985]), and at frequencies as high as $780 \mathrm{kHz}$ (from a broadcast transmitter at Santa Cruz, Argentina [Carpenter et al., 1984]). Most reported observations have amplitude changes ranging from $0.04 \mathrm{~dB}$ [Carpenter et al., 1984] to $6 \mathrm{~dB}$ [Helliwell et al., 1973] and phase changes as high as $12^{\circ}$ [Inan and Carpenter, 1987].

[8] What follows is a brief history of LEP observations and theory.

\subsection{History of LEP Research}

[9] Early detections of electron precipitation were made from rockets and satellites: Rycroft [1973] observed a single electron burst event on a rocket that was associated in time with an observed whistler, marking the first connection between lightning and radiation belt electrons. Goldberg et al. [1986] simultaneously observed a lightning flash and electron precipitation on a rocket, and noted that the lightning-induced 
precipitation of electrons $>40 \mathrm{keV}$ overwhelmed that produced by the nearby $21.4 \mathrm{kHz}$ NSS transmitter.

[10] Voss et al. [1984] were the first to document a direct connection between satellite measurements of transient (1 s) enhancements of loss cone electrons directly correlated with whistlers observed at Palmer Station, Antarctica. They found flux increases of two orders of magnitude over the background in energies of 45-200 keV. These events were analyzed in more detail by Voss et al. [1998], who found that these LEP events were caused by ducted whistlers, and calculated that a single LEP burst of $10^{-3} \mathrm{erg} \mathrm{s}^{-1} \mathrm{~cm}^{-2}$ depleted $\sim 0.001 \%$ of the particles in the affected flux tube. Using the SAMPEX satellite, Blake et al. [2001] found enhancements of drift loss cone electron fluxes in the range $150 \mathrm{keV}$ to $1 \mathrm{MeV}$ directly associated with thunderstorms. Most recently, Inan et al. [2007] made observations of LEP on the DEMETER satellite, constraining the electron energies to $100-300 \mathrm{keV}$, and directly correlated the events with lightning data from a ground-based network. Furthermore, these results demonstrated enhanced precipitating fluxes when the satellite passed over thunderstorm regions.

\subsubsection{Subionospheric VLF Probing}

[11] Perturbations to VLF transmitter signals have been observed since the use of such transmitters began, and have been correlated with geomagnetic storms for many decades [e.g., Bracewell et al., 1951; Potemra and Rosenberg, 1973]. Numerous authors [Lauter and Knuth, 1967; Belrose and Thomas, 1968] have suggested that such perturbations were caused by enhancements of the $D$ region nighttime electron density due to precipitating electrons with energies $>40 \mathrm{keV}$. The first direct connection between sudden changes in the VLF transmitter amplitude and phase and lightning-induced whistlers was made by Helliwell et al. [1973], who postulated cyclotron resonance between the electrons and the whistler wave as the mechanism for electron precipitation. Lohrey and Kaiser [1979] reported phase perturbations that suggested a counterstreaming interaction exclusively (no costreaming interaction) between the whistler waves and the radiation belt electrons.

[12] Inan et al. [1985] and Inan and Carpenter [1986, 1987] used phase and amplitude perturbations to VLF transmitter signals to interpret event sizes in terms of predicted precipitation fluxes, to associate events with one-hop whistlers, and together with a single-mode propagation theory, inferred precipitated fluxes of $10^{-4}-10^{-2} \mathrm{erg} \mathrm{cm}^{-2} \mathrm{~s}^{-1}$. Inan and Carpenter [1987] found that amplitude perturbations require a factor of $\sim 3$ larger ionospheric perturbation compared to phase perturbations, making the latter far more regularly observed. Inan et al. [1988a] used the subionospheric method to show that LEP events can involve precipitation of $>1 \mathrm{MeV}$ electrons, due to the observation of events on paths at $L \leq 1.8$ and an unusually fast recovery, suggestive of low-altitude energy deposition. Inan et al. [1988b] provided the first direct and extensive association between many tens of LEP events and individual cloud-toground lightning flashes, and Inan et al. [1988c] discussed the importance of longitude dependence of the bounce loss cone edges in both hemispheres. Inan et al. [1989] compared results of a test particle model with observations of an LEP event on the SEEP satellite to calculate the pitch angle and energy distribution of precipitated electrons. Simultaneous observations of ionospheric disturbances in the Northern and Southern hemispheres were made by Burgess and Inan [1990, 1993], showing that both hemispheres can be affected by the same lightning event.

[13] Dowden and Adams [1988] observed that most LEP events display positive phase changes and negative amplitude changes. These are in agreement with the single-mode theory of Inan and Carpenter [1987]: precipitation lowers the ionospheric reflection height, typically resulting in increased absorption, and thus negative $\Delta A$, and negative $\Delta h$, the ionospheric reflection height. They further show that phase changes $\Delta \phi \sim-1 / \Delta h$, so a negative $\Delta h$ makes a positive phase change. They go on to attribute negative phase to interference between multiple modes. Dowden and Adams [1988] further noted the shift from North to South (in the Southern Hemisphere, i.e., poleward) of the precipitation region in time. Dowden and Adams [1989] also noted that mode interference in the Earth-ionosphere waveguide may change the sign of the phase or amplitude change. Using two receivers and monitoring two VLF transmitter frequencies only $100 \mathrm{~Hz}$ apart, Dowden and Adams [1990] and Adams and Dowden [1990] were able to make estimates of the distance along the path to LEP events, placing them over active lightning regions.

\subsubsection{Implications for Optical Detection of LEP}

[14] While most of the work cited above concentrated on precipitation of $100-300 \mathrm{keV}$ electrons, as those reach to $D$ region altitudes to be probed by subionospheric techniques, Jasna et al. [1992] calculated whistler-induced precipitation of $\sim 100 \mathrm{eV}$ electrons, and showed that they may constitute 30 times larger energy fluxes with the same input wave power density. This prediction may be significant for optical detection of LEP events, a method which can observe higher altitudes and lower-energy electrons; some early optical observations of precipitation induced by magnetospheric chorus emissions have been made by Helliwell et al. [1980] at Siple Station of the $4278 \AA$ emission from Nitrogen, and by Doolittle and Carpenter [1983] at the conjugate point in Roberval, Québec. The first detection of optical emissions from LEP is yet to be made; however, the intensity is expected to be very low on account of low particle fluxes, in comparison with natural aurora, and the time scales are immensely shorter $(\sim 1 \mathrm{~s}$ for a single LEP event, versus minutes or hours for auroral displays). Peter and Inan [2007] find that LEP precipitation peaks at $10^{-2}$ ergs $\mathrm{s}^{-1} \mathrm{~cm}^{-2}$ for a $100 \mathrm{kA}$ lightning discharge, while the precipitated flux associated with visible aurora is generally in the range $0.1-10 \mathrm{ergs} \mathrm{s}^{-1} \mathrm{~cm}^{-2}$ [e.g., Meng, 1976; Rees, 1992].

\subsubsection{Ducted or Nonducted Whistlers?}

[15] The question of whether ducted or nonducted whistlers are involved in LEP events, or both, has been a topic of great interest. Observations of both ducted and nonducted whistlers was first made by the OGO 1 satellite [Smith and Angerami, 1968]. These provided evidence of the presence of both types of whistlers in the magnetosphere, while only ducted whistlers are thought to be able to reach the ground [Helliwell, 1965]. This experiment also discovered the magnetospherically reflecting (MR) whistler [Edgar, 1976]. Burgess and Inan [1993] studied 74 perturbations to subionospheric VLF, LF, and MF signal paths, and found that 

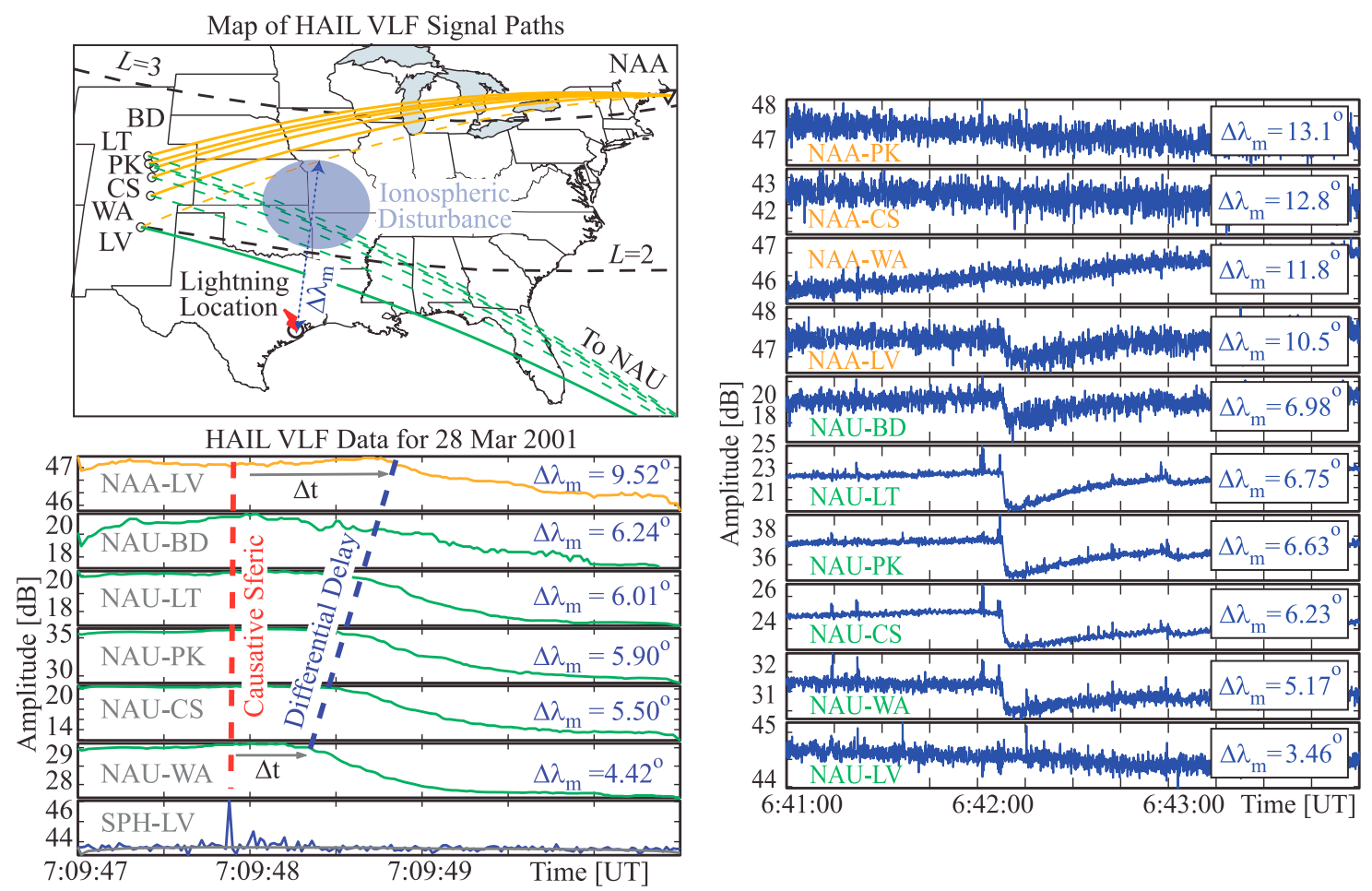

Figure 2. Example LEP events on 28 March 2001. Taken from Peter [2007]. (top left) Map showing the location of the causative lightning discharges and the HAIL great circle paths. (bottom left) Data for an event at 0709:48 UT. (right) Data for another event at 0642:01 UT.

every perturbation was time-associated with a ducted whistler. They went on to estimate that ducted whistlers contribute as much as plasmaspheric hiss to radiation belt losses, assuming every ducted whistler causes precipitation.

[16] Poulsen et al. [1993b, 1993a] present the first 3-D, multimode model of subionospheric VLF propagation in the Earth-ionosphere waveguide, utilizing the Long Wave Propagation Capability (LWPC) code [Pappert and Snyder, 1972; Ferguson and Snyder, 1987]. This model enables simulation of ionospheric disturbances off the GCP from transmitter to receiver; Poulsen et al. [1993a] show that disturbances $\sim 50 \mathrm{~km}$ in radius must be within $\sim 250 \mathrm{~km}$ of the $6000 \mathrm{~km}$ path, and that this transverse displacement from the path depends on both the disturbance size, the path length, and the transmitter frequency. Lev-Tov et al. [1995] used the model of Poulsen et al. [1993b] to compare simulations with observed LEP events, and from comparisons extracted information about the altitude profiles of both the ambient electron density and the disturbed ionosphere.

\subsection{Holographic Imaging of Precipitation Regions}

[17] The concept of VLF "imaging" was proposed by Inan [1990]. Therein, the authors used observations at three receiver locations from six VLF transmitters in North America, and the resulting grid of criss-crossing great circle paths, to deduce the precipitation region of an LEP event. Similarly, Dowden and Adams [1993] used an array of five receivers in New Zealand, monitoring the NWC transmitter, to find north-south dimensions of $100-250 \mathrm{~km}$ for LEP disturbances.

[18] An algorithm for "holographic imaging" using an array of receivers oriented along a meridian was developed by Chen et al. [1996]. This concept was taken to fruition by Johnson et al. [1999b, 1999a], through the development of the Holographic Array for Ionospheric Lightning (HAIL). Johnson et al. [1999a] went on to use the HAIL array to make accurate measurements of size $(\sim 1000 \mathrm{~km}$, in agreement with model calculations from Lauben et al. [1999]) and location of precipitation regions, showing both poleward displacement from the lightning strike and a tendency toward increasing delay from the lightning strike with increasing latitude (as shown in Figure 2, bottom left). These observations provided definitive evidence of oblique whistler propagation. This oblique propagation and poleward displacement was modeled by Lauben et al. [1999, 2001], using the ray-tracing and wave-induced particle precipitation (WIPP) codes of Inan and Bell [1977]. Other experimental work in determining the size of precipitation patches has been conducted using an array of VLF receivers on the Antarctic peninsula [Clilverd et al., 2002], who estimate regions of $600 \mathrm{~km}$ in latitude by $1500 \mathrm{~km}$ in longitude.

[19] Extensive studies of LEP events were conducted at Stanford in recent years using data from the HAIL array. Peter and Inan [2004] looked at statistics of LEP events during two $4 \mathrm{~h}$ storms and found onset delays, poleward displacement, and event durations as expected from nonducted whistler propagation. Peter and Inan [2005] studied LEP events associated with Atlantic hurricanes (Isabel 2003 and others), but found no indication that the hurricaneassociated lightning is more likely to induce electron precipitation events than lightning associated with other storm systems. Finally, Peter and Inan [2007] compared HAIL data of LEP events with modeling results to determine the ionospheric electron density perturbation corresponding to 

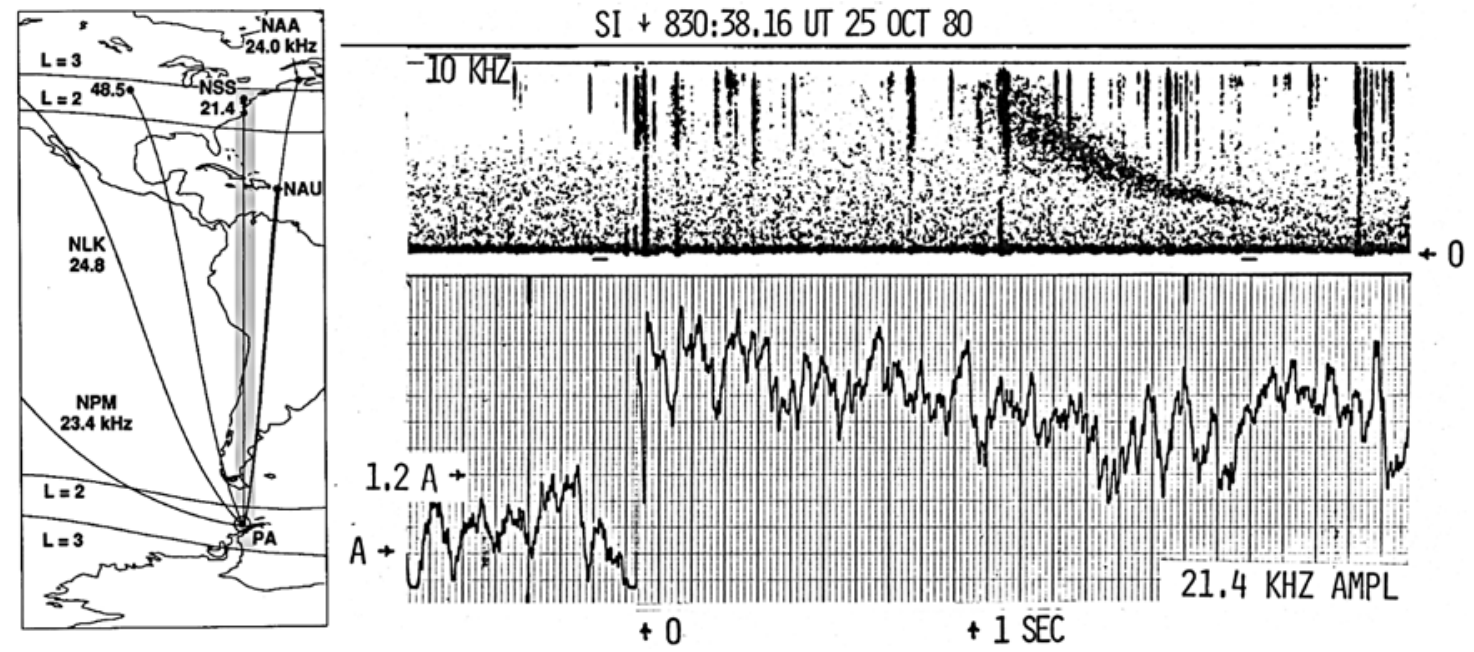

Figure 3. Example of the first early/fast events observed by Armstrong [1983]. (left) The geometry of the problem, where a storm just south of the NSS transmitter affects the path of that transmitter to Palmer Station, Antarctica. (top right) Palmer broadband VLF data in spectrogram form. A lightning-generated sferic is observed at $0 \mathrm{~s}$, and an associated sferic is detected $1 \mathrm{~s}$ later. (bottom right) The narrowband data from Palmer, exhibiting an early/fast event with zero delay from the causative sferic.

LEP events, and found enhancements of $\sim 15 \%$ at $85 \mathrm{~km}$ altitude, consistent with Lev-Tov et al. [1995] and Clilverd et al. [2002]. They also calculated that $0.006 \%$ of the electrons in a flux tube with energies $100-300 \mathrm{keV}$ were precipitated, which can be compared to Voss et al. [1998], who calculate $0.0015 \%$ of electrons with energies $>45 \mathrm{keV}$.

[20] An example with two LEP events is shown in Figure 2, taken from Peter [2007]. The data below the map, for an LEP event at 0709:48 UT on 28 March 2001, demonstrate the differential delay from the lowest latitudes to the highest. The event at right, an LEP event on the same day at 0642:01 UT, shows how the HAIL array is used to measure the latitudinal extent of the precipitation region, as the NAU-LV and NAA-WA paths are unaffected.

\subsection{Global Rates of Lightning-Induced Electron Precipitation}

[21] One of the most important outstanding questions regarding LEP pertains to its global contribution as a sink for relativistic particles in the radiation belts. With that goal in mind, some recent work has focused on quantifying the global effects of LEP. Clilverd et al. [2004] were able to relate the amplitude of subionospheric VLF perturbations, and the precipitated flux, to the causative lightning peak current. They showed that only $70 \mathrm{kA}$ and larger strokes created detectable LEP events. Rodger et al. [2005] used as estimate of the precipitated flux $\left(1-2 \times 10^{-3} \mathrm{ergs} \mathrm{cm}^{-2} \mathrm{~s}^{-1}\right.$, from Rodger [2003]), and the global rate of lightning, to estimate the rate of precipitation over the globe. They concluded a mean rate of $3 \times 10^{-4} \mathrm{ergs} \mathrm{cm}^{-2} \mathrm{~min}^{-1}$, with peaks as high as $6 \times 10^{-3} \mathrm{ergs} \mathrm{cm}^{-2} \mathrm{~min}^{-1}$ over active regions.

[22] The potential impact of LEP on radiation belt electron densities, especially those in the $\sim 100 \mathrm{keV}$ to $1 \mathrm{Mev}$ range, makes them an important area of study. Using the Inan et al. [1997] WIPP code, Bortnik et al. [2003] has suggested that magnetospherically reflecting (MR) whistlers may play an important role in the formation and maintenance of the slot region, and Bortnik et al. [2006a, 2006b] made estimates of the differential number flux of particles precipitated from the radiation belts by MR whistlers. Future work is needed to compare these model results with observations of whistlers, precipitating electrons, and LEP events on the ground. Such studies are beginning in recent years with satellites such as DEMETER [e.g., Inan et al., 2007], but further long-term studies are needed to accurately assess the effects of lightning on radiation belt populations.

\section{Early VLF Events}

[23] The delay of $\sim 1 \mathrm{~s}$ from the lightning return stroke to the onset of the VLF amplitude or phase change is a key feature of LEP events; it is the time required for VLF whistler mode waves to propagate to the equatorial region of the radiation belts, plus the time for energetic electrons to travel from the equatorial region to the lower ionosphere. Armstrong [1983] was the first to report events that exhibited a delay of $<100 \mathrm{~ms}$ (i.e., within the time resolution of the recording system), precluding any involvement with the magnetosphere or plasmasphere. An example of such an event is shown in Figure 3. These events were labeled "early" or "early/fast" VLF events by Inan et al. [1988b], who noted that (1) the "early" events were most often positive amplitude changes while LEP events (or classic VLF perturbation events) were negative; (2) they were confined to the early part of the night analyzed, while LEP events came later in the night; (3) the events had rise times of anywhere from $<50 \mathrm{~ms}$ up to $2 \mathrm{~s}$; (4) a number of events had "step-like" amplitude changes with no observed recovery; and (5) a direct coupling mechanism must be responsible for the observed short delay. However, the authors were unable to suggest a likely mechanism for these events. The "fast" moniker for these events denotes their usually rapid rise time to reach their full perturbation; however, slower rise times have been observed since Inan et al. [1988b], though 

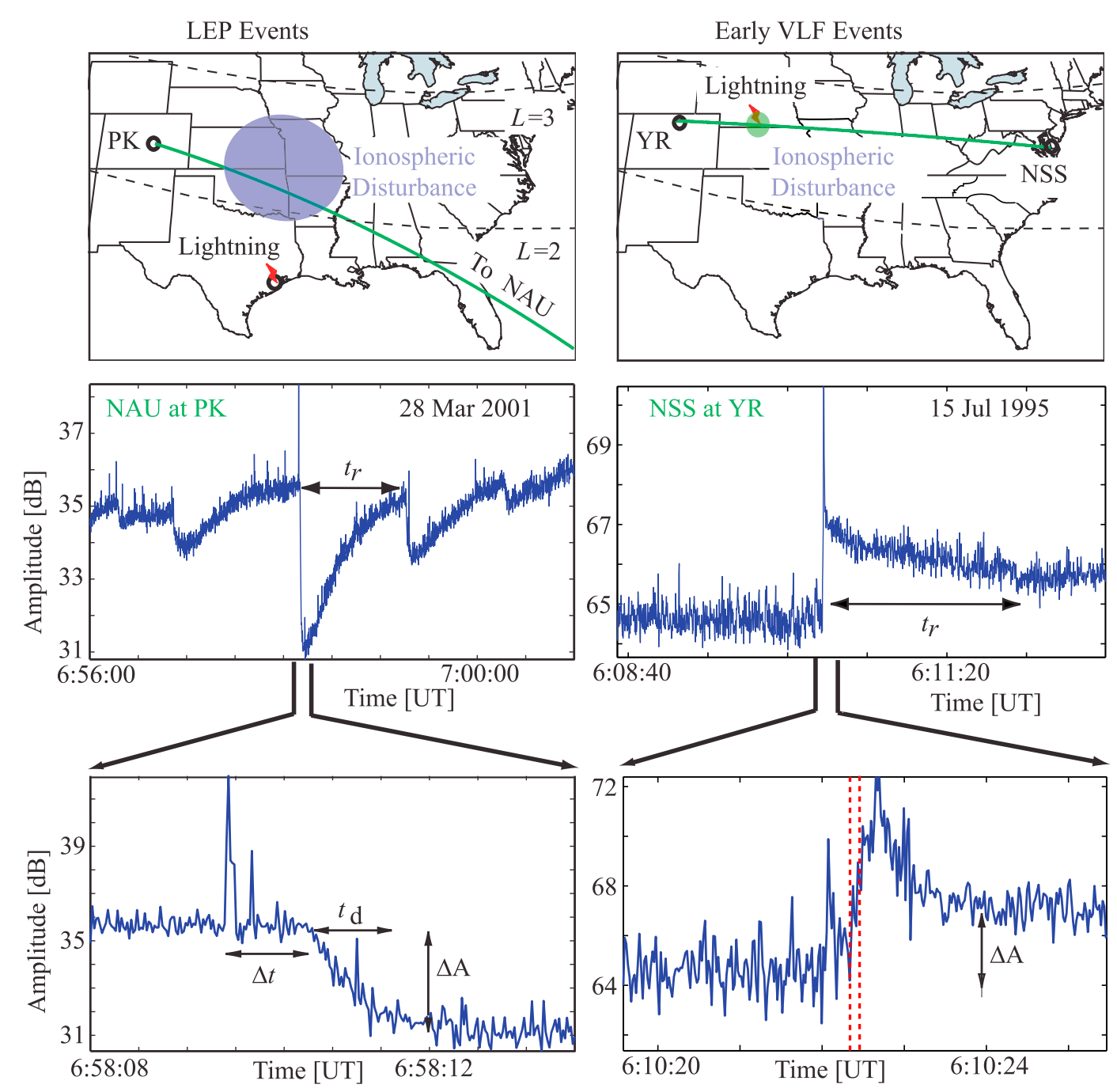

Figure 4. (left) LEP events and (right) early events contrasted. LEP events are displaced poleward from the causative discharge, are delayed up to $1-2 \mathrm{~s}$, and are most commonly negative $\Delta A$. Adapted from Peter [2007]. Early events, on the other hand, occur directly above the causative discharge and affect a much smaller region; they have $<100 \mathrm{~ms}$ delay from the causative CG (between the red dashed lines) and are most commonly positive $\Delta A$.

they were not considered in detail until recent years, as discussed later in this section. Figure 4 compares the salient features of early VLF and LEP events, using actual data from the HAIL array.

[24] Inan [1990] conducted an experiment wherein a VLF transmitter with $100 \mathrm{~kW}$ of radiated power at $28.5 \mathrm{kHz}$ in Puerto Rico was used to directly heat the lower ionosphere. The heating modulation was observed on the NAA transmitter signal propagating subionospherically from Cutler, Maine to Palmer Station, Antarctica, where the great circle path runs directly through the location of the Puerto Rico transmitter. This result was interpreted as a VLF analog of the Luxembourg effect [Tellegen, 1933], and the authors noted that similar heating should occur due to lightning, whose fields in the ionosphere were measured by Kelley et al. [1985] to be much larger than those of VLF transmitters. However, the authors also noted that the slow recoveries of the Inan et $a l$. [1988b] "early" events suggested ionization production, and thus other mechanisms in addition to heating.
[25] Shortly thereafter, Inan et al. [1991] produced the first model of heating and ionization of the $D$ region ionosphere by lightning. Using estimated peak fields of $E_{100}=$ 5-20 V/m (the electric field normalized to $100 \mathrm{~km}$ distance), they considered a Maxwellian electron energy distribution and its modification due to the lightning EMP electric field. That paper also predicted that the EMP-ionosphere interaction would lead to "airglow." Taranenko et al. [1992, 1993a, 1993b] used a 1-D fully kinetic model to account for the evolving electron energy distribution due to EMP heating of electrons, and furthermore calculated optical emissions due to the EMP. These models were the first to calculate direct effects of lightning in the $D$ region ionosphere, and numerically predict what we now know as elves.

[26] The discovery of sprites in 1989 [Franz et al., 1990] and elves in 1991 [Boeck et al., 1992] created a surge of interest in the direct lightning-ionosphere interaction. Inan et al. [1995] made the first correlation between sprites and "early" events, and suggested that the physical processes 

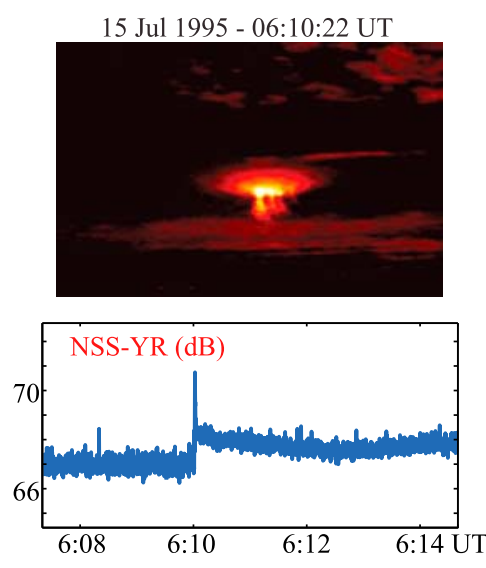
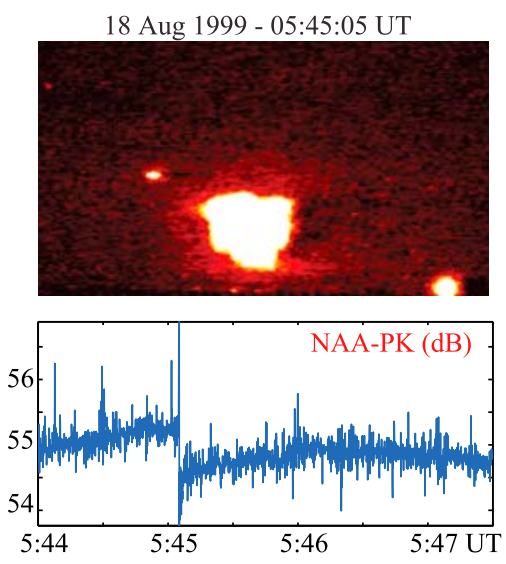

03 Jul $2000-06: 45: 33$ UT
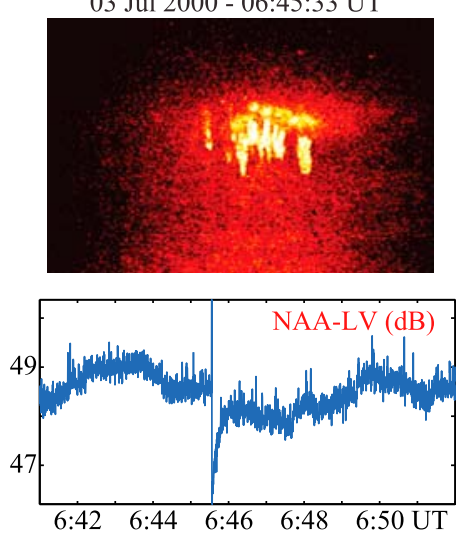

Figure 5. Examples of sprites and simultaneous early VLF events. From Marshall and Inan [2006].

that lead to sprites (i.e., quasi-electrostatic (QE) heating [Pasko et al., 1995; Pasko, 1996]) also alter the conductivity of the lower ionosphere; such ionospheric modifications were later calculated by Pasko et al. [1998a]. Note that while elves are thought to be caused exclusively by the lightning EMP, Adachi et al. [2004] showed that, at least in the case of "columniform" sprites, the EMP may contribute to their production in addition to the $\mathrm{QE}$ field. The major problem with the QE mechanism for early/fast events is that ionization requires a very strong electric field $(\sim 15 \mathrm{~V} / \mathrm{m}$ in the ionosphere), which can be produced by only the largest sprite-producing discharges. While heating requires a lower field intensity, the $\sim 10-100 \mathrm{~s}$ recovery time of early/fast events is not consistent with heating, which recovers in less than a few seconds.

[27] Meanwhile, Dowden et al. [1994] predicted that VLF phase and amplitude perturbations could be caused by VLF scattering from the plasma in the sprite body itself, and Dowden et al. [1996a] provided experimental evidence in favor of this mechanism. This led Dowden et al. [1996b] to use the scattered VLF signal to "detect" and locate sprites, assuming that every sprite scattered the VLF signal. Using this assumption, Hardman et al. [1998] used VLF perturbation measurements at a number of sites to determine the polar scattering pattern of a sprite, and compare it to a model of the sprite as a network of plasma columns [Rodger et al., 1997, 1998; Rodger and Nunn, 1999]. A more detailed discussion of so-called "VLF sprites," the signature of VLF scattering from sprite columns, can be found in the reviews by Rodger [1999] and Rodger [2003]. However, the sprite scattering mechanism suffers from two problems: early/fast events have recovery times of 10-100 s, consistent with ionization recovery at $\sim 80-90 \mathrm{~km}$ altitude, inconsistent with sprite altitudes; and Johnson et al. [1999b] observe most early/fast events as forward scattering, consistent with $\sim 100-150 \mathrm{~km}$ scattering regions.

[28] Adding to the list of candidate mechanisms, Inan et al. [1996a] suggested that the ionosphere could be held in a state of "sustained heating" due to the charge imbalance in, and thus resulting QE field above, intense thunderstorms; this sustained heating would then be regularly perturbed by lightning discharges, modifying the charge distribution, and in turn the QE field. This mechanism, however, was not able to produce the amplitude changes observed in early/fast events. Veronis et al. [1999] and Barrington-Leigh et al. [2001] used a 2-D finite difference model (including both EMP and QE effects through Maxwell's equations and the Poisson equation, respectively) to calculate the nonlinear effects in the $D$ region ionosphere due to lightning fields, computing both optical emissions and electron density disturbances. Barrington-Leigh et al. [2001] showed that sprite halos occur at $D$ region altitudes and are produced by the QE field, implying a connection with early/fast events. Moore et al. [2003] used the LWPC model to simulate the amplitude and phase changes measured as "early" events that correspond with halos; however, this mechanism again could not produce observed amplitude changes.

[29] In other experimental work, measurements at multiple VLF receiver sites using the HAIL array [Chen et al., 1996] allowed Johnson et al. [1999b] to show that the scattered signal was constrained to the forward direction, implying a scattering region that is smooth and large compared to the VLF wavelength. The authors were further able to constrain the lateral size of direct ionospheric disturbances to $\sim 90 \pm 30 \mathrm{~km}$. Given the later-observed scale sizes of $\sim 10-300 \mathrm{~m}$ in sprite features [Gerken et al., 2000; Marshall and Inan, 2005], these observations of forward scattering were inconsistent with the Dowden et al. [1994] theory of scattering from the sprite itself, which should be isotropic; however, a few cases of backscattering were reported by Marshall et al. [2006] which may have been caused by scattering in the sprite body. Figure 5 shows examples from Marshall et al. [2006] of early VLF events associated with sprites and sprite halos, some of which exhibited backscatter-like signatures.

[30] Detailed studies of VLF perturbations in Europe began with the series of "EuroSprite" campaigns, beginning in 2000 [Neubert et al., 2001, 2005, 2008]. The VLF results of these campaigns has been summarized by Mika and Haldoupis [2008]. From these campaigns, Haldoupis et al. [2004] reported a one-to-one correspondence between sprites and early/fast events. Haldoupis et al. [2006] later reported a new class of event; like early events it had no delay from the causative lightning discharge, but had a slow ( 1-2 s) onset time like LEP events. These would come to be known as "early/slow" events (shown in Figure 6), and 


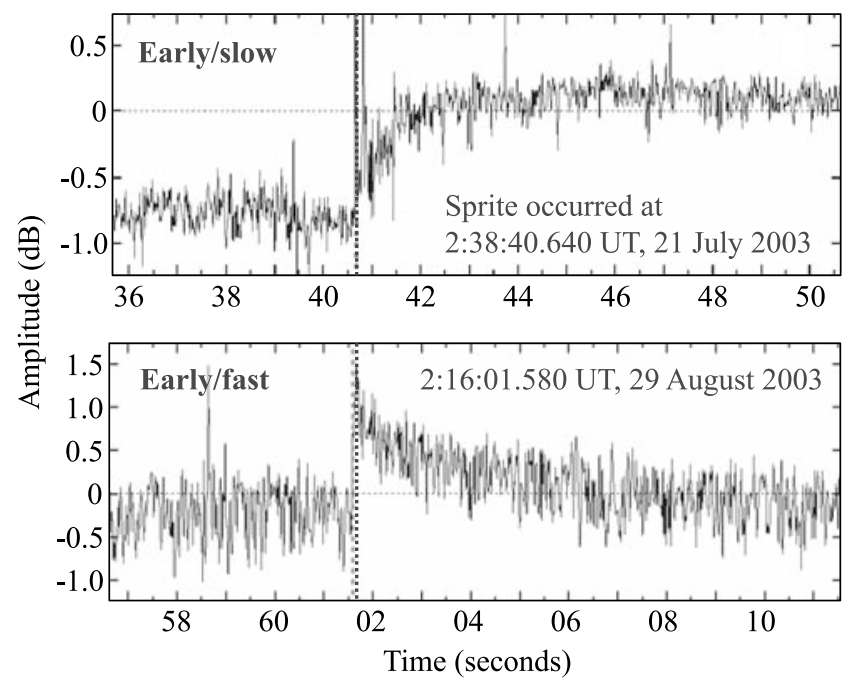

Figure 6. Contrasting examples of early/fast and early/ slow events. From Haldoupis et al. [2006].

the whole class of direct lightning-induced ionospheric disturbances would be reclassified as "early" events. The Haldoupis results led Marshall and Inan [2006] to revisit early event data from the mid-1990s; they then concluded that sprites and early/fast events were not one-to-one correlated in those U.S. storms, but in fact many sprites occurred without early events, and vice versa.

[31] Mika et al. [2006] observed a small fraction of elves that had associated early events, bringing back the potential for the EMP mechanism of Taranenko et al. [1993a]. This led Marshall et al. [2008a] to suggest in-cloud (IC) lightning EMP, manifested in a burst of lightning pulses, to create a cumulative ionization effect in the $D$ region. This mechanism could explain the early/slow events of Haldoupis et al.
[2006]. Marshall et al. [2010] provided in-depth modeling of the in-cloud EMP interaction with the ionosphere, and Marshall and Inan [2010] used a finite difference frequency domain (FDFD) model of the VLF transmitter signal propagation to show that the resulting disturbances could be measured by VLF receivers with observed amplitude changes. This work showed that bursts of in-cloud lightning could be responsible for early/slow events and some early/fast events.

[32] Recently, a new class of event has been catalogued by Cotts and Inan [2007], dubbed "long recovery" events, due to their surprisingly long recovery times of up to $20 \mathrm{~min}$ (Figure 7). These events were presented in prior publications [Inan et al., 1988b, 1996c; Dowden et al., 1997], but went mostly unnoticed. The authors suggested that low-altitude persistent ionization of heavy negative ions, as calculated by Lehtinen and Inan [2007], could be the cause, and could imply an association with gigantic jets [Pasko and StenbaekNielsen, 2002; Su et al., 2003]. However, the generation mechanism and detailed chemistry of these events remains poorly understood.

[33] Despite the 25 years of research since their discovery, the mechanism of "early" event production remains uncertain and a topic of current research. The long list of candidate mechanisms above may each be valid under certain conditions and for certain causative discharges, but an accurate account of those conditions remains to be established.

\section{Lightning EMP-Ionosphere Interaction}

[34] The results of Inan et al. [1991] and Taranenko et al. [1993a, 1993b] cited above were the first to suggest that lightning might directly affect the lower ionosphere, producing both ionization and optical emissions which we know as elves. After their initial discovery from the Space Shuttle [Boeck et al., 1992], the first ground observations of elves were made by Fukunishi et al. [1996] and Inan et al.
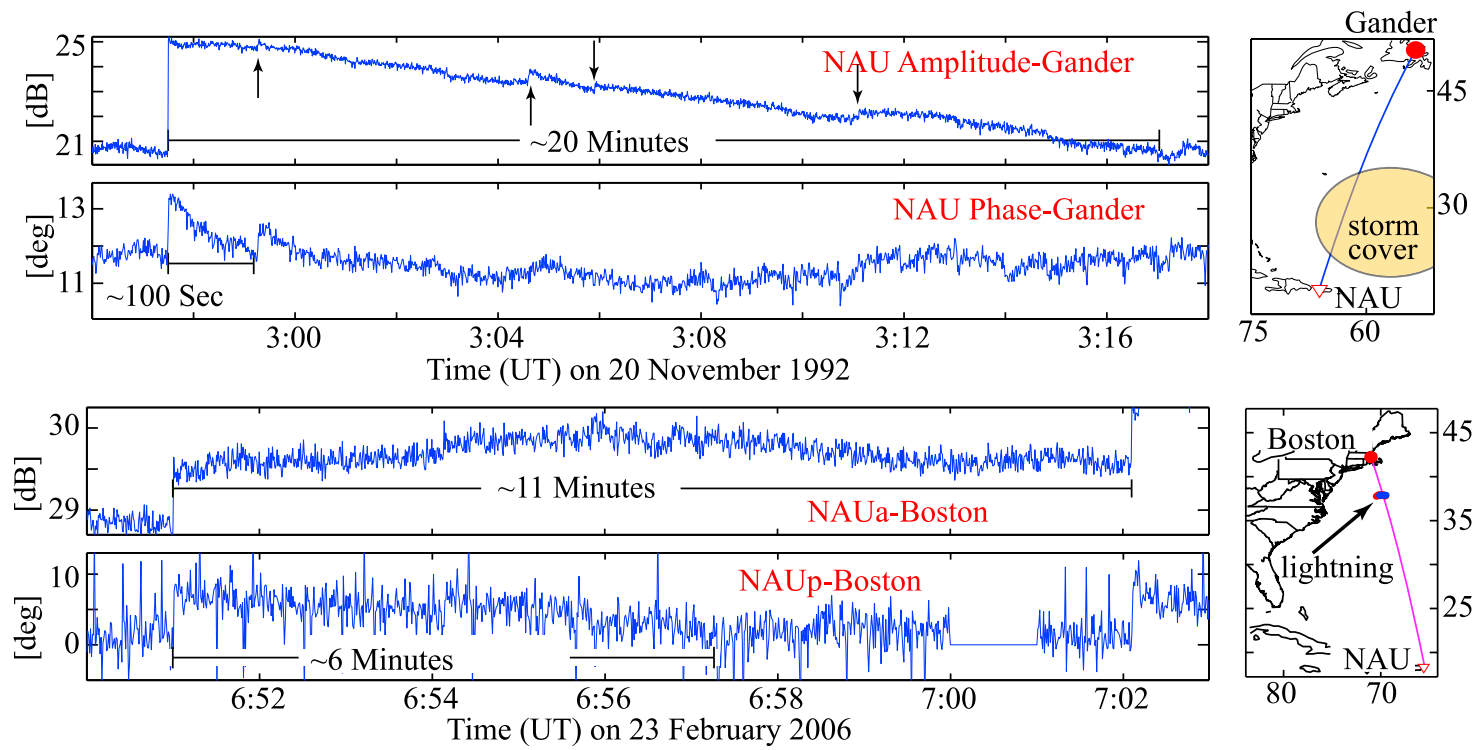

Figure 7. (top) Long recovery and (bottom) step-like early VLF events. From Cotts and Inan [2007]. In the LR event, note that a long recovery in amplitude can sometimes occur simultaneously with a standard $\sim 100 \mathrm{~s}$ recovery in phase. In the step-like event, the amplitude shows no discernible recovery, but the phase recoveries in a long $6 \mathrm{~min}$. 


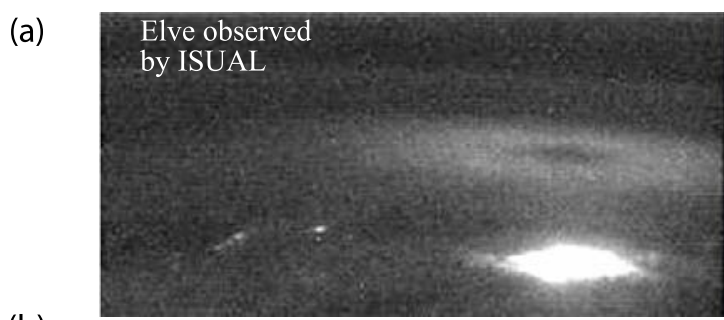

(b)
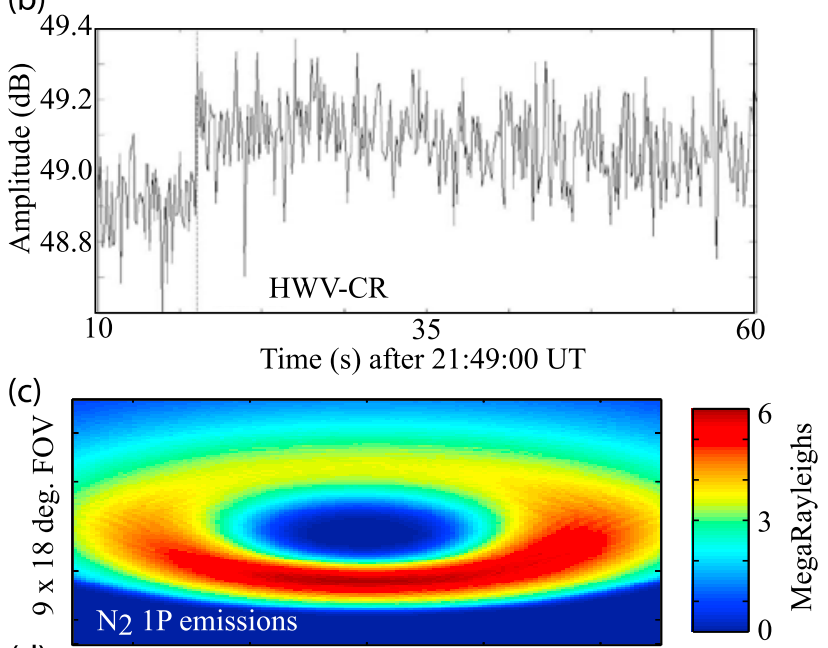

(d)

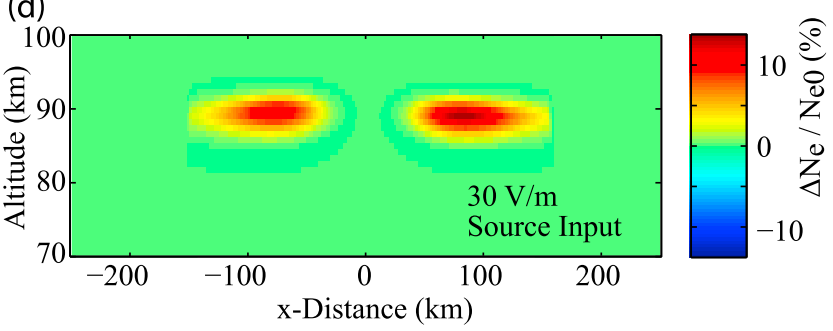

Figure 8. (a) Elve observed by ISUAL and (b) simultaneous early/fast event observed on the HWV signal at Crete. From Mika et al. [2006]. (c) Optical emissions in $\mathrm{N}_{2} 1 \mathrm{P}$ band system and (d) electron density changes predicted for an $E_{100}=30 \mathrm{~V} / \mathrm{m}(100 \mathrm{kA}) \mathrm{CG}$ discharge. From Marshall et al. [2010].

[1997] using photometry. Furthermore, Inan et al. [1997] predicted the 2-D shape of elves, having the signature donut shape, a signature of the dipole-like radiation pattern of the causative cloud-to-ground lightning discharge. Recently, the ISUAL instrument aboard the FORMOSAT-2 satellite (formerly known as ROCSAT-2 [Chern et al., 2003]) has shown that elves are globally far more common than previously thought; where ground-based cameras might see one or two elves for every 10 sprites, satellite and ground-based photometry observe 6-8 times as many elves [Chen et al., 2008]. Ground-based measurements using the PIPER photometer array [Marshall et al., 2008b] show a similar preponderance of elves over individual storms [Newsome and Inan, 2009], compared to the global statistics of ISUAL.

[35] Modeling of elves in 2-D has been undertaken by Cho and Rycroft [1998], Veronis et al. [1999], and BarringtonLeigh et al. [2001] and in three dimensions by Cho and Rycroft [2001] and Marshall et al. [2010]. These models have all shown that the lightning EMP can significantly modify the lower ionospheric electron density, with disturbances persisting for 10-100 s. The 3-D models cited above have shown the possibility that horizontal, in-cloud lightning discharges may also affect the lower ionosphere. Furthermore, along the lines of the argument by Adachi et al. [2004] above, Rodger et al. [2001] used the 2-D model of Cho and Rycroft [2001] to suggest that successive lightning EMPs could precondition the lower ionosphere for subsequent sprite initiation; this mechanism was proposed to explain the lack of sprites at the beginning of sprite-producing thunderstorms.

[36] Mende et al. [2005] used observations of elves in multiple wavelength bands, with multiple energy thresholds, to estimate a reduced electric field of 200 Townsend $(1 \mathrm{Td}=$ $10^{-21} \mathrm{~V} \mathrm{~m}^{2}$, given by $\mathrm{E} / \mathrm{N}$, the local electric field divided by the local neutral density; $200 \mathrm{Td}$ corresponds to $12.7 \mathrm{~V} \mathrm{~m}^{-1}$ at $90 \mathrm{~km}$ altitude) in the region of the elve, and from that an ionization production of $\sim 200$ electrons $\mathrm{cm}^{-3}$ averaged over a volume of $150 \mathrm{~km}$ radius and $10 \mathrm{~km}$ thick. This was the first measurement, though indirect, of ionization in the lower ionosphere directly caused by lightning EMP.

[37] The first evidence of VLF scattering associated with elves was reported as a single rapid-onset, rapid-decay (RORD) [Dowden et al., 1994]) event associated with an elve [Hobara et al., 2001]. The possibility that elve-related ionization could be measured with the subionospheric VLF technique was investigated in greater detail by Mika et al. [2006]. It was found therein that a subset of elves (5 out of 5 observed from the ground, and 3 out of 17 observed from ISUAL) have associated "early" events; an example of one such event is shown in Figure 8, along with modeling results from Marshall et al. [2010] for comparison. However, it should be noted that these associations do not account for the possibility of in-cloud lightning activity (see section 6). Cheng and Cummer [2005] and Cheng et al. [2007] used broadband VLF signals from lightning strokes that occurred just before and just after high peak current strokes to detect, via VLF scattering, the electron density perturbations that are produced through the lightning-EMP process. They estimated electron density disturbances through this approach that agreed well with those measured optically by Mende et al. [2005]. Furthermore, Marshall and Inan [2010] model VLF perturbations due to elve-associated ionization for CG discharges of $E_{100}=15-40 \mathrm{~V} / \mathrm{m}$ (peak currents of 50$133 \mathrm{kA}$ ), and show that only the largest input amplitudes $(30 \mathrm{~V} / \mathrm{m}$ and above) yield measurable VLF perturbations.

[38] Future work in the study of the lightning EMPionosphere interaction will lead to a number of new insights. First, global (via satellite) and local (ground) optical monitoring of elves will lead to a better understanding of the interaction, and as models mature, the optical measurements can be used as a proxy for ionospheric disturbances. These comparisons will also yield implications of whistler wave injection into the magnetosphere, as the processes are intertwined. Long-term global observations and more robust models are needed in order to accurately quantify these interactions.

\section{ELF and VLF Signatures of TLE-Producing Lightning}

[39] The above sections describe how man-made VLF signals have been and continue to be used to detect and 

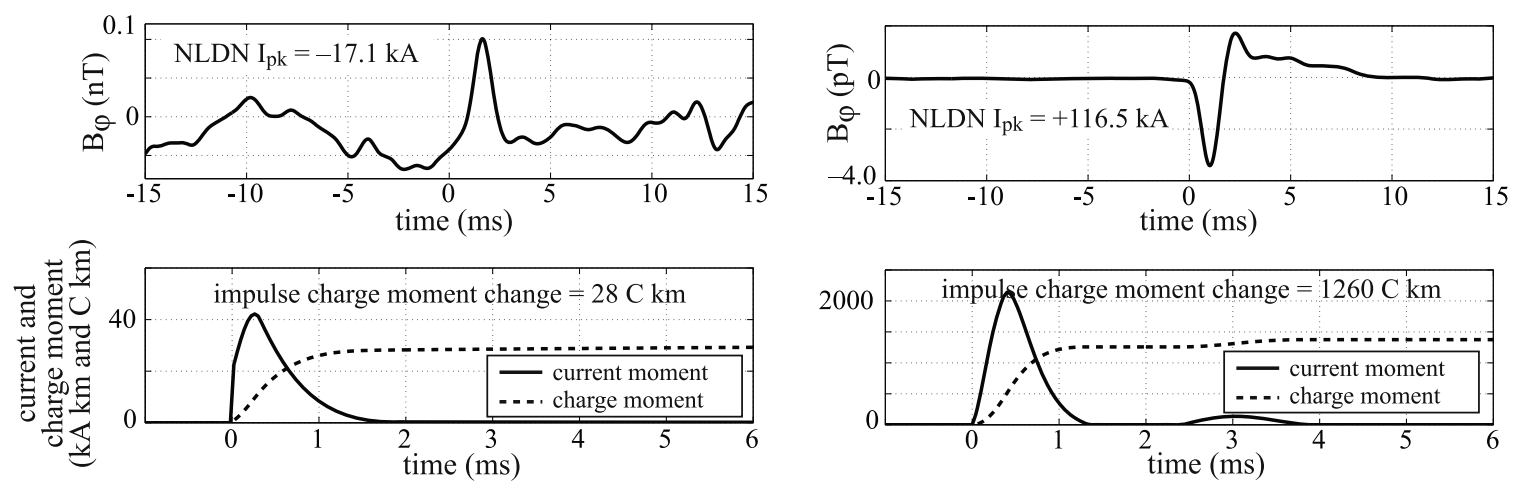

Figure 9. Strong ELF radiation from sprite-producing lightning. The ELF $(<1 \mathrm{kHz})$ amplitudes of (left) typical and (right) sprite-producing lightning vary by more than a factor of 35 , while the peak currents vary only by a factor of 7 . This reflects the relatively much larger total charge moment change in the sprite-producing stroke compared to the typical stroke. Adapted from Cummer and Lyons [2005].

measure the ionospheric effects of lightning and TLEs. In an entirely different manner, one can also use the natural VLF and lower-frequency radio emissions from lightning itself to probe and measure the currents and charge transfer in the lightning responsible for generating TLEs. And, in some cases, radio emissions from the TLEs themselves can provide insight into their internal processes.

\subsection{Sprite-Producing Lightning}

[40] An obvious and important open scientific question after sprites were first discovered [Franz et al., 1990] concerned the characteristics of the lightning capable of producing such a spectacular phenomenon, or indeed whether they were even connected with individual lightning strokes. To address this, a method was needed to identify and probe lightning strokes that may occur at long range from a sensor. Fortunately, lightning is a very powerful radiator of electromagnetic energy from VLF and LF [Rakov and Uman 2003, p. 6] all the way down to the Schumann resonance band of a few $\mathrm{Hz}$ [Besser, 2007], and it has been well known for decades that electromagnetic waves at these low frequencies can travel extremely long distances while guided by the Earthionosphere waveguide [Barr et al., 2000]. The typical sensorto-sprite distances of hundreds to thousands of $\mathrm{km}$ makes VLF and lower-frequency measurements an ideal tool for studying TLE-producing lightning.

[41] Boccippio et al. [1995] were the first to apply this general idea to measuring the low-frequency signatures of TLE-producing lightning. They found that sprites were nearly one-to-one associated with strong, positive polarity Schumann resonance transients, indicating that sprites were associated with positive polarity lightning involving significant total charge transfer to the ground. This observation was in good agreement with the theory of Pasko et al. [1995] that sprites were driven largely by the quasi-static component of the postlightning electric field, an idea that had been conceptually put forth long ago by C. T. R. Wilson (see Huang et al. [1999] for a brief historical summary). Price et al. [2002] used ELF transients to geolocate spriteproducing lightning, and Price et al. [2004] expanded the analysis to include four stations; what they found, paradoxically, were ELF transients associated with elves, but not with sprites, contradictory to the theory of Pasko et al.
[1995]. Sato and Fukunishi [2003] used Schumann resonance transients to geolocate sprite-producing lightning, and used their statistics to derive sprite occurrence rates.

[42] Reising et al. [1996] found that ELF and VLF signals produced by sprite-associated lightning flashes contained an unusually large amount of radiated energy between roughly 100 and $500 \mathrm{~Hz}$, indicating substantial cloud-to-ground charge transfer in these flashes on millisecond and longer time scales. Other reports also confirmed this basic finding [Cummer and Inan, 1997; Bell et al., 1998; Füllekrug and Reising, 1998; Huang et al., 1999], and Figure 9 shows some sample ELF waveforms that exhibit this basic finding. This early work essentially confirmed that sprites were driven by high-altitude electric fields created by strong charge moment change lightning.

[43] These early qualitative measurements of spriteproducing lightning also showed that the strokes appeared to be of exclusively positive polarity. This observation supported two competing theories behind sprite production: conventional breakdown [Pasko et al., 1995, 1997], which is not polarity dependent, and relativistic runaway breakdown [Bell et al., 1995; Taranenko and Roussel-Dupre, 1996], which requires downward electric fields and thus positive polarity lightning. Not until 1999 were confirmable negative polarity sprites reported [Barrington-Leigh et al., 1999], and with just a small number more observed [Taylor et al., 2008] they remain rare, apparently due to the relative infrequency of very high charge moment change negative lightning [Williams et al., 2007]. Based on the existence of negative polarity sprites along with clear observations that sprites are composed almost entirely of small-scale streamers [Gerken et al., 2000], as predicted by conventional breakdown theory [Pasko et al., 1998a], it is generally accepted that conventional breakdown creates essentially all of the observable optical emissions in sprites. VLF and lowerfrequency measurements of lightning played a key role in achieving this qualitative understanding.

\subsection{Elve-Producing Lightning}

[44] The lightning that produces elves, which are large (hundreds of $\mathrm{km}$ in diameter) but very brief (tens of microsecond duration) expanding rings is quite different from that which produces sprites. Elves are known to be 
generated through the nonlinear interaction between the ionosphere and the lightning electromagnetic pulse [Taranenko et al., 1993a; Inan et al., 1997], and it is the peak amplitude of the electric field on time scales of tens of microseconds in the lower ionosphere that drives the phenomenon. The interaction is nonlinear in that ionization and optical emission rates vary nonlinearly with the applied electric field. Although the peak fields in the ionosphere are not identical to the peak fields observed in ground altitude sferics, they are linked. Consequently, elve-producing lightning produces ground-observable sferics with very high peak VLF electromagnetic fields and high reported peak currents. This was first investigated qualitatively by Fukunishi et al. [1996], who were the first to observe elves. BarringtonLeigh et al. [1999] found a strong link between NLDNreported peak current, peak VLF sferic fields, and elve brightness that is in close agreement with simulations, thereby confirming the basic physics responsible for elve optical emissions. Indirect measurements of the ionization created in elves have been based on detailed analysis of optical spectra [Mende et al., 2005; Kuo et al., 2007] and from broadband VLF sounding of the lower ionosphere [Cheng et al., 2007], and these independent measurements are remarkably consistent [Cheng et al., 2007].

[45] There remain a few puzzling observations of elves, however, that are not well-explained, such as elves that lack the "donut hole" in the center that is produced by the radiation pattern of a vertical current source. Israelevich et al. [2004] observed a number of such events from the Columbia Space Shuttle and attributed the lack of "donut hole" to in-cloud lightning (i.e., a horizontal dipole) as a source. However, ground-based observations of elves produced by in-cloud lightning, either vertically or horizontally oriented, have not yet been definitively made.

\subsection{Halo-Producing Lightning}

[46] Halos are a diffuse, high-altitude optical emission driven by lightning that occur at generally lower altitudes than elves, develop more slowly than elves, and lack the telltale hole in the center. Barrington-Leigh et al. [2001] were the first to realize that they are a phenomenon distinct from elves, and through simulations and high-speed video showed convincingly that halos are produced by strong lightning-driven mesospheric electric fields at relatively high altitudes where the field does not persist long enough to create streamers. Many bright sprites are superposed on a halo Barrington-Leigh et al. [2001], and highspeed video observations show that sprite streamers can form from an instability at the lower edge of a halo [Cummer et al., 2006b], a process that has also been modeled in detail [Luque and Ebert, 2009]. Isolated halos without clear sprite streamer structures are also observed from the ground [e.g., Moudry et al., 2003] and from space [Chen et al., 2008].

[47] The mechanism behind halo formation is thought to be relatively well understood because they lack the complex nonlinear behavior of streamers, and comparisons of halo modeling and observations agree extremely well [BarringtonLeigh et al., 2001]. It is interesting to note that the earliest attempts to simulate sprites [Pasko et al., 1995, 1997], which did not contain any streamer physics because at the time sprite streamers had not been identified, were effectively simulating halos before their discovery. According to theory and mod- eling [Barrington-Leigh et al., 2001], halos should produced by lightning containing relatively large charge moment changes on submillisecond time scales which are shorter than the time scale for streamer formation. A detailed study of the relationship of halo properties and those of the corresponding lightning has not been reported in the literature, however.

\subsection{Sprite Currents}

[48] VLF and lower-frequency radio emissions have played a role in additional TLE-related discoveries and continue to be used to study the processes associated with TLE-producing lightning. One of the first was that some events contain clearly detectable ELF signatures of significant charge transfer and current flow inside the sprites themselves, at high altitude. Cummer et al. [1998] first showed this through observations of submillisecond time alignment of ELF pulses observed in association with some sprites and high time resolution sprite photometer measurements. Similar comparisons that included high-speed sprite video [Cummer and Stanley, 1999] showed that these ELF sprite current pulses appear to originate during the expansion of the upward streamers in sprites that typically forms the brightest stage of sprite development [Stanley et al., 1999; Cummer et al., 2006b]. This same ELF sprite signature was used by Stanley [2000] to show that sprites may occur during the daytime following exceptionally large lightning discharges. Farges et al. [2005] made the first measurements of infrasound waves emitted from sprites, suggesting rapid heating within the sprite columns. Furthermore, they observed these infrasound signatures past sunrise, and suggested daytime sprites as the cause.

[49] Later, simultaneous observations of lightning and sprite optical emissions from the ISUAL instrument on the FORMOSAT-2 satellite [Chern et al., 2003] showed that the ELF pulses emitted by sprites were not associated with any visible low-altitude lightning process [Cummer et al., 2006a]. These observations confirmed that high-altitude sprite currents produce this class of ELF pulse. It was also shown that the time variation and magnitude of the observed ELF sprite pulses are consistent with what would be produced by a sudden enhancement in mesospheric electric conductivity from the sprite [Pasko et al., 1998b]. Why these sprite current pulses are only easily seen in some sprites, and what their existence implies for charge motion in the context of sprite streamers, remains not well understood.

\subsection{Continuing Current and Sprites}

[50] With the basic understanding of sprite-associated lightning strokes provided by the measurements described above, research has continued to probe the detailed time variation of the large charge transfer observed in spriteproducing lightning. Cummer and Inan [1997] and Bell et al. [1998] showed through ELF measurements that shortduration continuing current of tens of $\mathrm{kA}$ for several milliseconds is present in most sprite-producing lightning strokes. Through even lower frequency measurements from $<1$ to $100 \mathrm{~Hz}$, Cummer and Füllekrug [2001] showed through a quasi-static magnetic signature that unusually large (current moment of 20 to $60 \mathrm{kA} \mathrm{km}$ ) long-duration continuing currents lasting tens to hundreds of $\mathrm{ms}$ are present in at least some sprite-producing lightning flashes. Even larger long 
continuing currents, the largest of which was a current moment of $120 \mathrm{kA} \mathrm{km}$ that lasted for more than $100 \mathrm{~ms}$, have been reported in more recent measurements of spriteproducing lightning flashes [Li et al., 2008]. These measurements provided observational evidence of the long continuing currents needed to explain the observation that some sprites initiate tens to hundreds of milliseconds after a lightning return stroke [Bell et al., 1998; Huang et al., 1999]. Low-frequency electromagnetic measurements provide the capability to measure these long continuing currents with relatively high time resolution $(\sim 1-2 \mathrm{~ms})$ with sensors that are $1000 \mathrm{~km}$ or more away from the lightning of interest [Ross et al., 2008]. Interestingly, however, when comparing measurements of ULF transients below the Schumann resonance (i.e., below $7.8 \mathrm{~Hz}$ ) for sprite-producing and nonsprite-producing lightning, Bösinger et al. [2006] found no unique signature for sprite-producing lightning, contrary to the results cited above. Similarly, Greenberg et al. [2009] found that a significant number of sprite-producing lightning events $(33 \%)$ had no ELF transients, suggesting that long continuing current may not always be a necessary condition for sprite production.

\subsection{Other Lightning Processes and Sprites}

[51] VLF and lower-frequency measurements have also been used to study the relationship of TLEs with other lightning processes. Bursts of VLF radiation called sferic bursts have also been observed in many sprite-producing discharges [Johnson and Inan, 2000] and whose role in producing sprites continues to be studied. This topic is discussed in detail in section 6. M components, which are intensifications in continuing current on time scales of a fraction of a millisecond to many milliseconds [Rakov and Uman, 2003, p. 176], have been shown theoretically to potentially play a role in the initiation of sprites and sprite halos [Yashunin et al., 2007]. The significant role of $\mathrm{M}$ components in the initiation of long-delayed sprites was shown with measurements by $L i$ et al. [2008], who found $\mathrm{M}$ components are associated nearly one to one with sferic bursts, and that the nonlinear ionospheric conductivity response [Pasko et al., 1997] to electric fields produced by measured M components [Yashunin et al., 2007] produces an anomalously large mesospheric electric field enhancement that is large enough to push the field to near-breakdown levels. This same process has also been studied with numerical simulations by Asano et al. [2009], who also used simulations to show that the precise form and timing of charge removal from the cloud, even for the same net charge, also help control the shape of sprites (i.e., carrot versus columniform). Their work also clearly demonstrated that the importance of $\mathrm{M}$ component timing and magnitude mean that charge moment change quantity by itself is not necessarily a good measure of the effect of lightning on the mesosphere because the precise details of how the charge transfer occurs in time play a critical role.

\subsection{Using ELF Content to Extract Current Moment}

[52] Early theories [e.g., Pasko et al., 1997] made specific predictions regarding the lightning charge moment change required to initiate sprites that could be tested with quantitative measurements. These predictions drove and continue to drive interest in measuring this quantity from remotely measured electromagnetic fields. At VLF and lower frequencies, the effective source of distant $(>100 \mathrm{~km})$ electric fields is the lightning vertical current moment (current integrated along the lightning channel height), not just the current, because the lightning channels are comparable or shorter than an electromagnetic wavelength. Current moment can be simply integrated in time to yield charge moment change, which makes remotely measured low-frequency sferics well-suited to making the measurements needed to test sprite initiation theories.

\subsubsection{Early Sprite-Associated Charge Moment Change} Measurements

[53] Cummer and Inan [1997] first reported measurements of charge moment change in sprite-associated lightning strokes through the analysis of the ELF component of sferics from $\sim 50 \mathrm{~Hz}$ to $1 \mathrm{kHz}$. They found charge moment changes that ranged from 250 to $3250 \mathrm{C} \mathrm{km}$ over the first $5 \mathrm{~ms}$ of the lightning strokes. Bell et al. [1998] used a similar approach and noted the existence of short continuing current $(\sim 1 \mathrm{~ms})$ in these strokes, and found comparable charge moment changes of 100 to $1100 \mathrm{C} \mathrm{km}$ over the first $15 \mathrm{~ms}$ of the lightning strokes. Using lower-frequency Schumann resonance measurements ( $\leq 50 \mathrm{~Hz}$ ), Huang et al. [1999] measured total charge moment changes over the entire duration of sprite-producing strokes of roughly 200 to $2000 \mathrm{C} \mathrm{km}$. It is important to realize that these charge moment changes were measured on a range of time scales, from a few ms to hundreds of $\mathrm{ms}$, and are thus not directly comparable. Nevertheless, these measurements confirmed that the lightning in at least some sprite-producing strokes was at least as large as predicted theoretically.

[54] Although some observed charge moment changes were interpreted as unexpectedly small based on the most current predictions of the time, the fundamental streamer nature of sprites was only just beginning to be recognized. Streamers enable sprite optical emissions to extend down to altitudes where the electric field is significantly smaller than the conventional breakdown threshold [Pasko et al., 1998a], improving the consistency of smaller charge moment changes with observations. There are reports of sprites produced by lightning charge moment changes that are small in the context of conventional breakdown [Cummer, 2003; Hu et al., 2007] and suggest that additional factors might play a role in the initiation of some sprites [Pasko et al., 1997; Zabotin and Wright, 2001]. Collectively, however, these early measurements of charge moment changes in sprite-producing lightning showed conclusively that the charge moment changes in sprite-associated lightning strokes are generally large enough to generate sprites according to quantitative model predictions.

\subsubsection{Techniques}

[55] Measuring lightning parameters from distant electromagnetic fields relies on the generally linear and timeinvariant nature of long distance VLF and lower-frequency propagation. In other words, the absolute amplitude of the received signal is linearly proportional, albeit in a complicated way due to propagation effects, to the absolute amplitude of the source. To use this to measure lightning, the electromagnetic signals must be measured with accurate absolute calibrations, and the effect of signal propagation must be modeled or known with high fidelity. Because different frequencies propagate through somewhat different 
mechanisms, different models are used in this process. Numerical mode theory codes [Ferguson and Snyder, 1987], analytical mode theory [Greifinger and Greifinger, 1979], and finite difference time domain codes [Hu and Cummer, 2006; Marshall and Inan, 2010] have been used to model propagation over nonglobal distances, while a variety of mode theory approaches [Ishaq and Jones, 1977; Sentman, 1990; Füllekrug and Constable, 2000; Mushtak and Williams, 2002] and numerical techniques [Simpson and Taflove, 2004; Yang and Pasko, 2005] have been used to model the global Schumann resonance band signals.

[56] With these pieces in place, the job becomes solving the inverse problem of estimating the source from known remote fields. Burke and Jones [1996] describe an approach using Schumann resonance band signals to globally measure charge moment changes in large lightning strokes. Other efforts to solve the inverse problem using Schumann resonance band measurements have used similar frequency domain inversion techniques [e.g., Huang et al., 1999; Sato et al., 2008]. Cummer and Inan [2000] describe a regularized deconvolution approach to this problem that they continue to apply in later work. Whatever technique is used, the basic approach is a powerful one for measuring current moment waveforms and charge moment changes in lightning that can be thousands of $\mathrm{km}$ from the sensors. It should be noted, though, that different signal frequencies provide different information about lightning source parameters. To measure the details of fast processes, such as the return stroke, requires signals on the order of several hundred $\mathrm{kHz}$ to match the few-microsecond time scale of the phenomenon. Slow processes, like long continuing currents of up to several hundred milliseconds, require sensors with a good response to a few $\mathrm{Hz}$ and below. Ideally one would measure as broad a bandwidth as possible to capture information on all relevant time scales. Global SR signals generally below $50 \mathrm{~Hz}$ can typically provide a two-parameter exponential fit to the source current moment waveform, which does not always accurately describe the true current moment waveform in sprite-producing lightning. Efforts have been made to include additional information about the lightning source to reduce this limitation [Adachi et al., 2008].

\subsubsection{Global, Regional, and Local Studies}

[57] Quantitative measurements of sprite-producing lightning continue for several goals. Global measurements of lightning charge moment changes from Schumann resonance band measurements are used to estimate the global occurrence and distribution of sprites [Füllekrug and Constable, 2000; Ignaccolo et al., 2006; Sato et al., 2008]. Other work has demonstrated the ability to geolocate and measure sprite-producing lightning on a global scale from a relatively small number of sensor locations (even as few as one) Price et al. [2002, 2004]. Such measurements continue to be a valuable tool for regional studies of sprite producing lightning as well [Hayakawa et al., 2004; Neubert et al., 2005; Yair et al., 2009]. Efforts have been made to use current moment measurements and sprite observations to define a charge moment change threshold for sprite initiation. Hu et al. [2002] analyzed 76 confirmably prompt sprites $(<10 \mathrm{~ms}$ from the lightning stroke) and found that a charge moment change of 600-1000 C km was very likely to initiate a sprite.

[58] Cummer and Lyons [2005] took the additional step of measuring the charge moment changes of lightning that did not produce sprites, and found consistency with a threshold of 350 to $600 \mathrm{C} \mathrm{km}$ for producing prompt sprites. Importantly, they found no large charge moment lightning strokes that exceeded this threshold but did not create a sprite. Interestingly and in disagreement with the above study, Bösinger et al. [2006] compared measurements of ULF transients below the Schumann resonance (i.e., below $7.8 \mathrm{~Hz}$ ) for sprite-producing and non-sprite-producing positive polarity lightning and found that the magnitude and shape of signals produced by $+C G$ strokes were essentially the same whether sprites were produced or not. Even more puzzling, Greenberg et al. [2009] found from a modest database of 15 sprites that a significant number (5) of sprite-producing lightning events produced no clear ELF transients observable with their sensors. The conclusions of these three papers are all different, and more studies comparing the low-frequency radio signatures of sprite-producing and non-sprite-producing discharges are clearly needed.

[59] Current moment waveforms in sprite-producing lightning measured from VLF and lower-frequency fields have also been used to estimate, using numerical simulations, the mesospheric electric fields responsible for sprite initiation. Hu et al. [2007] found that for visibly large and bright sprites, the electric field near $80 \mathrm{~km}$ altitude consistently reaches the conventional breakdown threshold, while for small and dim sprites, the maximum field under the assumption of lateral atmospheric and ionospheric homogeneity sometimes only reaches $20 \%$ of that value. Li et al. [2008] applied the same approach to long delayed sprites observed with highspeed video, and found a similar range of maximum mesospheric electric field at the observed time of sprite initiation.

[60] The use of VLF and lower-frequency signals to study TLE-producing lightning is not limited to ground-based measurements. Balloon-based measurements have provided additional constraints on the lightning parameters that produce TLEs [Thomas et al., 2005], and low-frequency radio emissions from TLE-producing lightning have now been observed from space as well [Blecki et al., 2009; Lefeuvre et al., 2009]. Regardless of observing platform, basic VLF and lower-frequency radio observations remain one of the most effective tools for measuring TLE-associated lightning.

\section{Sferic Bursts and IC Lightning}

[61] The VLF signatures of reasonably large $(>20 \mathrm{kA})$ cloud-to-ground lightning discharges are easily observed tens of Mm from the discharge, thanks to the efficient propagation in the Earth-ionosphere waveguide and the dipolelike radiation pattern, which is maximum along the ground. In-cloud (IC) lightning, on the other hand, which does not touch the ground, has a null at large range along the ground, whether it is horizontally or vertically oriented, due to interference from the ground reflection. Johnson and Inan [2000] were the first to notice signatures of in-cloud lightning in VLF data. Broadband $(0-20 \mathrm{kHz})$ VLF recordings show noise-like signatures, extending over the entire frequency range and lasting for hundreds of milliseconds up to one second, often coincident with a CG sferic. Referred to therein as "sferic clusters," the authors speculated IC lightning as the source, due to (1) the high attenuation of the cluster energy versus range and lack of observation at distances over $1000 \mathrm{~km},(2)$ the similarity with intracloud lightning flashes 
(a)
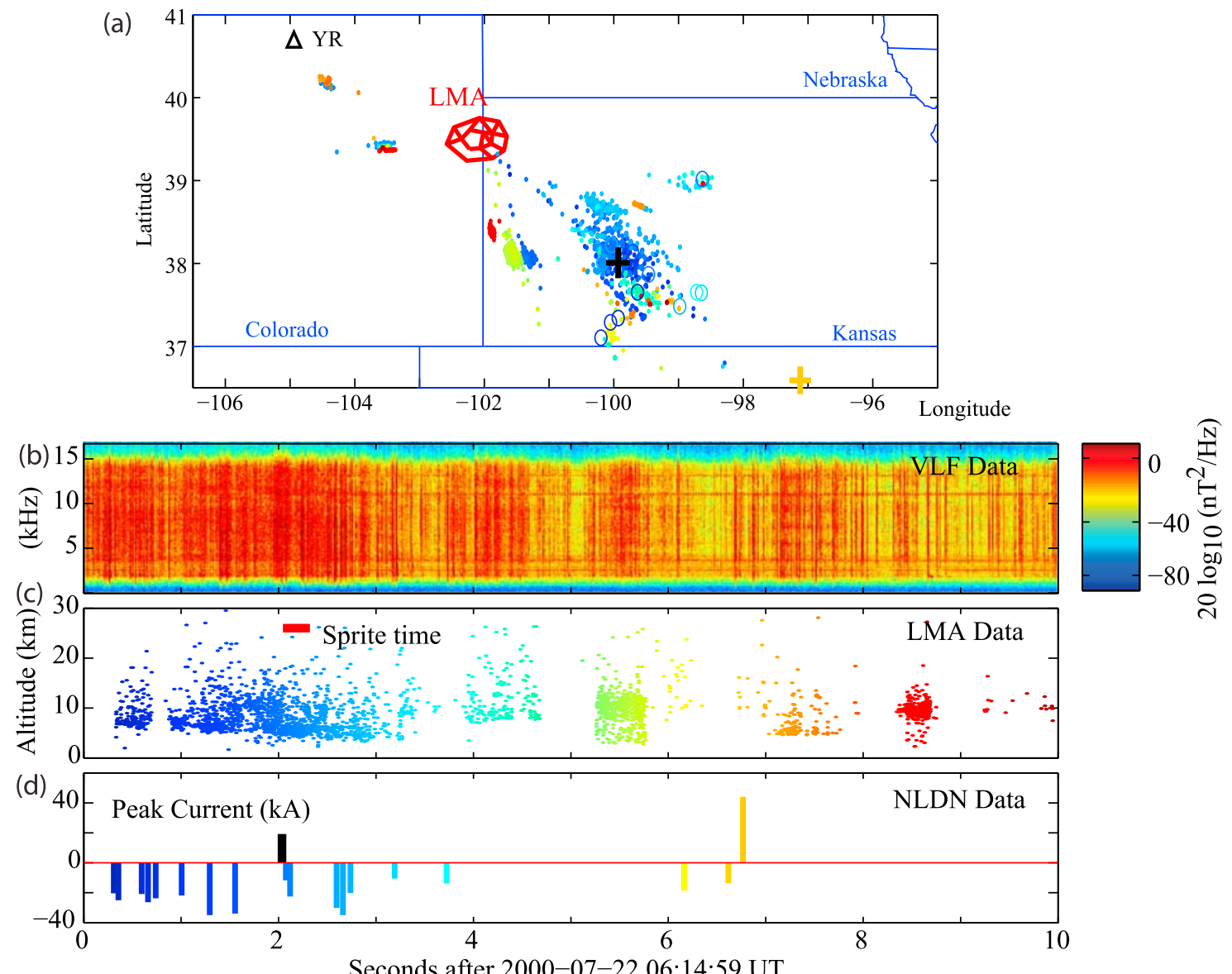

Seconds after 2000-07-22 06:14:59 UT

Figure 10. Example of a sferic burst. From Marshall et al. [2007]. (a) Map showing the location of the VLF receiver at Yucca Ridge (YR) and the Lightning Mapping Array (LMA), as well as locations of LMA-detected pulses, colored in time. (b) Broadband VLF data, exhibiting strong burst activity over most of this 10 s sample. (c) LMA pulses versus altitude. (d) NLDN-detected CG strokes.

reported by Shao and Krehbiel [1996], and (3) the lack of NLDN-reported CGs in each case.

[62] Ohkubo et al. [2005] compared broadband VLF data, showing evidence of sferic cluster activity, concurrent with observations of sprites, and argued for in-cloud lightning activity as a contributing mechanism toward sprite production. However, that argument hinged on the speculative connection between in-cloud lightning and sferic clusters. van der Velde et al. [2006] were the first to directly compare VLF broadband data with in-cloud lightning measurements using a SAFIR interferometric VHF system, and concluded that carrot sprites in particular were associated with IC activity based on the sferic cluster activity, though the SAFIR data did not provide a good correlation. Marshall et al. [2007] compared VLF broadband data recorded over the summer of 2000 with Lightning Mapping Array (LMA) data (a time-of-arrival system), and showed a direct connection between the LMA data and sferic bursts (as they are referred therein), with a high correlation coefficient. An example of this data is shown in Figure 10; it is evident from this example that the LMA pulses are strongly correlated in time with VLF burst activity. This provided the first direct correlation between in-cloud lightning measurements and VLF sferic cluster/burst activity. Li et al. [2008] combined VLF measurements of sferic bursts, ELF/ULF measurements of slow continuing currents, and high-speed sprite video to show that sferic bursts occur at the same time as M components, which are significant increases in the amplitude of the continuing current flowing from cloud-to-ground. They showed with detailed modeling that these observed $M$ components significantly enhance the mesospheric electric field and are likely responsible for initiating the observed sprites. This suggests that the observed association of sferic bursts and sprites is not causal, but is simply due to the association of in-cloud sferic bursts with M-components. In each of the four papers cited in this paragraph, the authors have used the VLF broadband data to investigate the role of in-cloud lightning in sprite production; and in the case of Marshall et al. [2007], that the in-cloud lightning contributes to "early" event production, as postulated by Johnson and Inan [2000].

[63] The connection between "early" events and in-cloud lightning has since been tested through modeling by Marshall et al. [2008b, 2010] and Marshall and Inan [2010]. In that sequence of papers, a 3-D time domain model is used to calculate the ionospheric electron density changes due to in-cloud lightning EMP pulses. Marshall and Inan [2010] then take those electron density changes and determines the amplitude perturbations that would occur on a VLF transmitter signal. Results show that in-cloud EMP could cause 
(a)

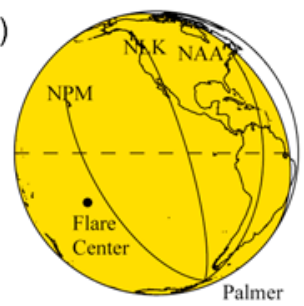

(b)

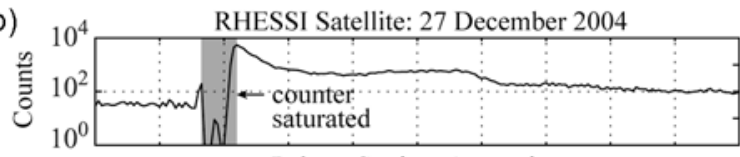

(c)
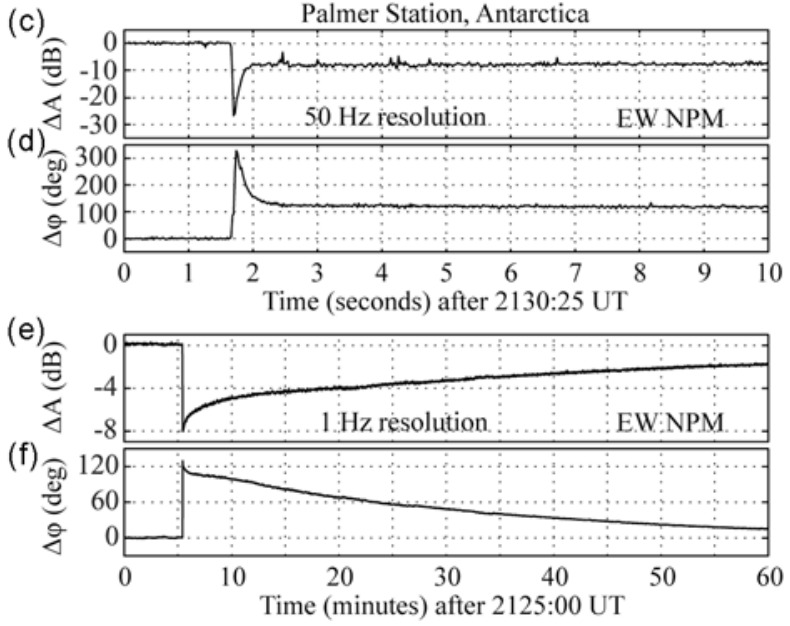

Figure 11. Gamma ray flare event. From Inan et al. [1999]. (a) VLF great circle paths from the NPM, NLK, and NAA transmitters to the VLF receiver at Palmer Station. The shading shows the region in daylight during the event. (b) Gamma ray counts on the RHESSI satellite. (c-f) VLF amplitude and phase narrowband signals observed at Palmer. Figures $11 \mathrm{e}$ and $11 \mathrm{f}$ are zoomed out in time to show the full hour-long recovery signature.

observable "early" events, and may be the source of the early/ slow events observed by Haldoupis et al. [2006].

[64] Haldoupis et al. [2006] similarly provide evidence that IC lightning activity is the source of early/slow events. However, their mechanism is through secondary ionization by the in-cloud EMP accelerating "seed" electrons produced by the QE field, while Marshall et al. [2008b] suggest direct ionization by the in-cloud EMP pulses. The Haldoupis model is based on their observed one-to-one association between "early" events and sprites.

[65] It has long been speculated that CG-associated IC activity (which is the case for the van der Velde et al. [2006], Ohkubo et al. [2005] and Marshall et al. [2007] events) serves to help "drain" the cloud of charge by sending it to the ground, enhancing the QE field that is responsible for sprite production. This has now been shown experimentally by Li et al. [2008] to be true for at least some sprites. However, van der Velde et al. [2006] observed IC activity in relation to carrot sprites but not to column sprites. As such, it may be that certain lightning discharges require this IC activity and associated long continuing current in order to drain enough charge to create a large enough $\mathrm{QE}$ field for breakdown, while in other cases (perhaps those that initiate column sprites), the impulsive charge moment of the CG alone is enough to lead to breakdown in the mesosphere. It should be emphasized that the nonlinearity that increases the electron attachment rate in the mesosphere in response to subbreakdown electric fields [Pasko et al., 1997] enables sprites to be created by nearly steady continuing currents by significantly increasing the local dielectric relaxation time. It has also been shown by combining measurements and modeling that this nonlinearity plays a key role in allowing high electric fields to be created at sprite initiation altitudes [Hu et al., 2007; Li et al., 2008].

\section{VLF Signatures of Gamma Ray Bursts}

\subsection{Extraterrestrial Gamma Rays}

[66] Radiation of extraterrestrial origin (X-rays from solar flares, for example) has long been known to affect the ionosphere [e.g., Kreplin et al., 1962; Mitra, 1974; Thomson et $a l ., 2005]$. Measurements of these phenomena by subionospheric VLF probing were made by Bain and Hammond [1975] as sudden phase anomalies. Brown [1973] made the first theoretical calculations of the ionospheric effects of gamma rays; however, ionospheric effects of gamma rays were not measured until 1983. One of the largest gamma ray bursts ever observed occurred at 2214:18 UT on 1 August 1983, observed by a number of satellites including ICE and the Vela spacecraft. Fishman and Inan [1988] reported a simultaneous, large perturbation to the $16 \mathrm{kHz}$ GBR (Great Britain) VLF transmitter signal received at Palmer Station, Antarctica. This observation is thought to be the first measurement of ionospheric response to an extrasolar influence.

[67] Inan et al. [1999] observed unusually large amplitude (24 dB at Palmer) and phase (65 degrees) changes on the NPM transmitter signal measured at Palmer Station, Boston, and across the HAIL array, caused by the magnetar SGR $1900+14$. Furthermore, the VLF signature exhibited the 5.16 second periodicity of the magnetar's rotation, and calculations showed that $90 \%$ of the total gamma ray burst energy was carried in a $3-10 \mathrm{keV}$ photon component that could not be measured by the Ulysses satellite that observed the gamma ray burst.

[68] Inan et al. [2007] report a massive disturbance in the daytime ionosphere due to the SGR 1806-20 gamma ray flare in December 2004, shown in Figure 11. The ionospheric disturbance, measured by the NPM transmitter signal at Palmer Station, lasted for over an hour, caused an $24 \mathrm{~dB}$ amplitude and 300 degree phase perturbation, and modeling showed that it affected the ionosphere down to $20 \mathrm{~km}$ altitude.

\subsection{Terrestrial Gamma Ray Flashes}

[69] Gamma ray bursts of terrestrial origin were unexpectedly discovered by the BATSE instrument on board the Compton Gamma Ray Observatory (CGRO) [Fishman et al., 1994], who attributed them to bremsstrahlung radiation, and found an association with thunderstorms. Smith et al. [2005] observed TGFs with energy spectra up to $20 \mathrm{MeV}$ on the RHESSI satellite, and observed that they occur most often over the three equatorial regions of Central America and the Caribbean, the Congo Basin, and Southeast Asia; satellite observations [Christian et al., 2003] show that these regions are also where lightning is most prevalent. 
(a)
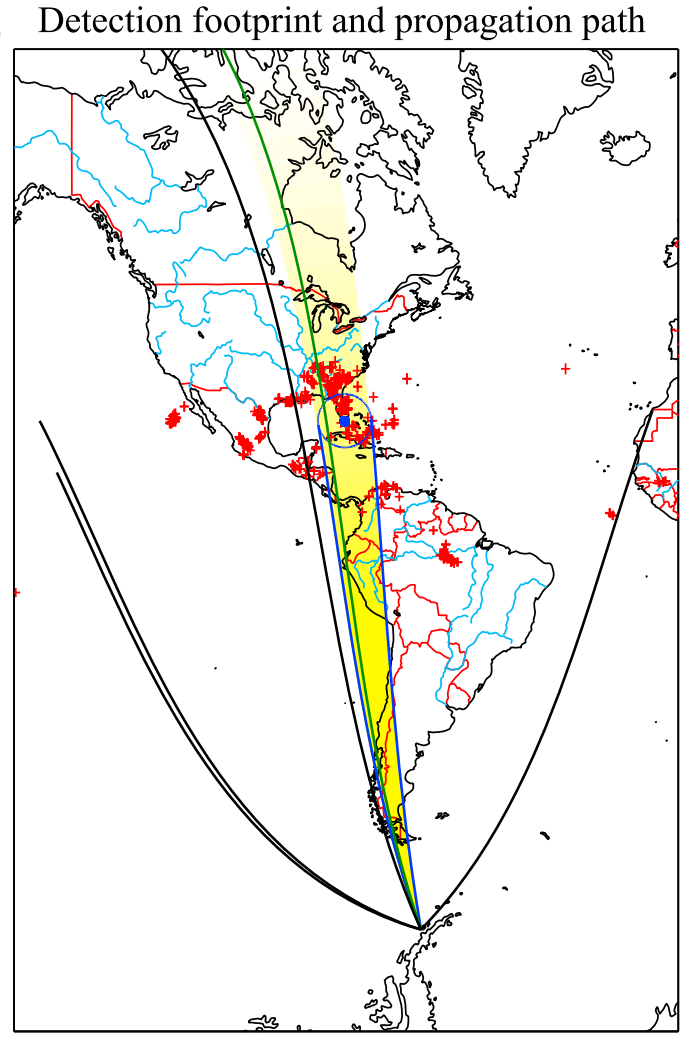

(b)
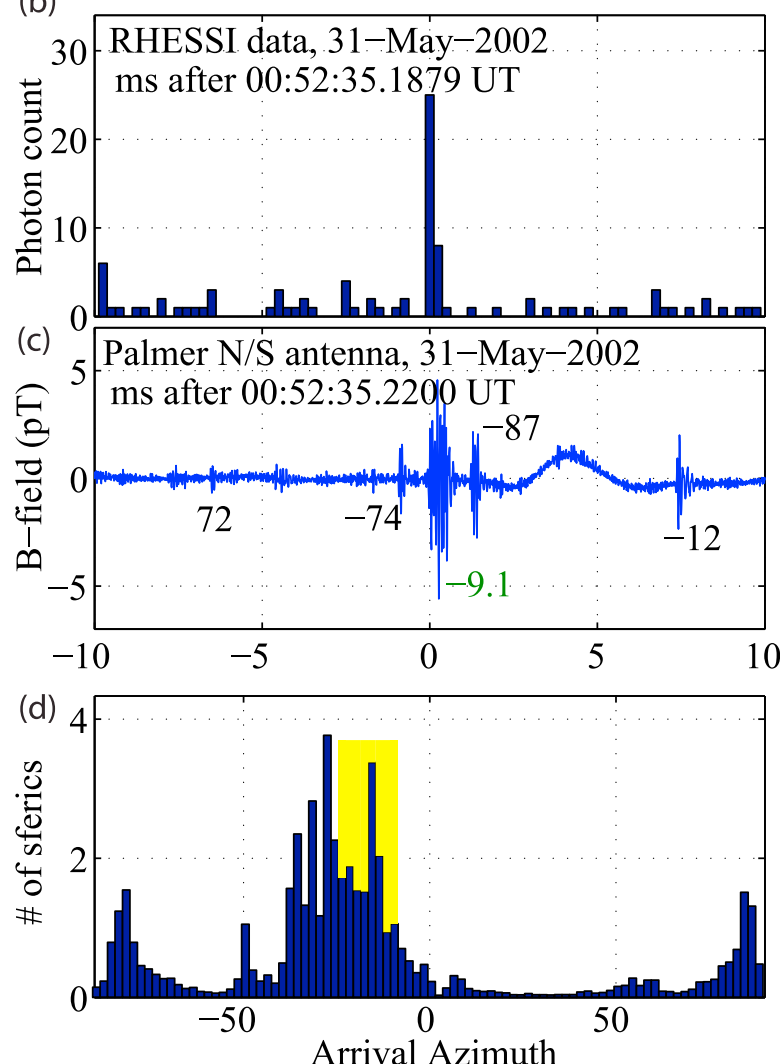

Figure 12. An example TGF with VLF sferic association, modified from Inan et al. [2006], including corrected RHESSI timing from Grefenstette et al. [2009]. See Cohen et al. [2010] for a modification of Figure 12. (a) Map showing the RHESSI footprint and propagation directions to Palmer Station. (b) RHESSI gamma ray counts. (c) VLF broadband sferic and direction-finding results. (d) Histogram of all sferics over a $30 \mathrm{~min}$ period.

[70] The possible association with lightning led to the use of VLF observations to verify or dispute this claim. Inan et al. [1996b] found evidence of a strong sferic within $1.5 \mathrm{~ms}$ of one TGF observed by BATSE, and showed evidence of a possible connection with sprites due to the slow-tail energy of the waveforms observed at Palmer Station.

[71] Cohen et al. [2006] conducted a comparative study using TGFs observed by the BATSE instrument, finding 6 TGFs (in addition to those analyzed by Inan et al. [1996b]) that had concurrent VLF data at Palmer Station, but only three of these had associated sferics. Inan et al. [2006] found that $76 \%$ of TGFs observed by RHESSI (of the 195 analyzed) occurred in association with sferics observed at Palmer Station; an example is shown in Figure 12. They found that TGF-associated sferics had among the largest peak currents, while the ELF content (and thus charge moment) were not especially large. This trend led Inan and Lehtinen [2005] to propose the production of TGFs by the EMP of a rapid lightning return stroke. They found, however, that peak currents of at least $450 \mathrm{kA}$ would be required to produce TGFs via this mechanism.

[72] Cummer et al. [2005] studied VLF sferics associated with 13 out of 26 TGFs detected by RHESSI, and found that all 13 were associated with positive CG discharges with charge moment changes, and thus quasi-static electric fields, too small to drive high-altitude runaway breakdown. Stanley et al. [2006] studied correlations between RHESSI TGFs and intracloud discharges as detected by the Los Alamos Sferic Array (LASA). Five of 8 TGFs analyzed had coincident IC discharges, and those were found to originate at $10-15 \mathrm{~km}$ altitudes. These observations are contrary to the EMP mechanism of Inan and Lehtinen [2005], and led Carlson et al. [2009] to a mechanism for TGF production involving intracloud discharges. While understanding of the specific mechanism or mechanisms for TGF production is still forthcoming, it is apparent that VLF sferic data has played, and will continue to play, a vital role in that understanding.

\section{Summary}

[73] In this review paper, we have presented a brief history of the use of subionospheric VLF probing as a technique for studying the lower ionosphere, and in particular the effects of lightning on the ionosphere and, indirectly, in the magnetosphere. Intense lightning discharges emit an electromagnetic pulse (EMP), which (1) propagates to distances of over $10,000 \mathrm{~km}$ in the Earth-ionosphere waveguide; (2) interacts with the lower ionosphere at $90 \mathrm{~km}$ altitude, causing heating, optical emissions, and new ionization; and (3) leaks through the ionosphere and into the magnetosphere, where its energy can interact with radiation belt electrons and cause some of those electrons to precipitate in the lower 
ionosphere at $60-100 \mathrm{~km}$ altitude. The direct lower ionosphere interaction and the precipitation signatures can be detected by subionospheric VLF remote sensing, wherein a VLF transmitter signal is used as a probe of the lower ionosphere, and disturbances are detected as rapid perturbations in the VLF amplitude or phase.

[74] In recent decades, the study of VLF signals, both the lightning-generated sferic and related VLF transmitter signals, has led to a greater understanding of the new phenomena known as TLEs, as described in section 5. Correlations of early VLF events with sprites and elves has helped in interpretation of the mechanisms of these events, while studies of the sferic signatures of the causative lightning events has led to an understanding of the type of lightning that initiates sprites, elves, jets, and TGFs.

[75] The very long distance propagation and strong interaction with the lower ionosphere are qualities that make VLF and lower-frequency signals a unique tool for probing the variability of the lower ionosphere driven by lightning from below and magnetospheric processes from above, and for probing the characteristics of the lightning that drives these phenomena.

[76] Acknowledgments. This work was supported by Office of Naval Research grant N00014-03-1-0333 and National Science Foundation grant ATM-0551174, ATM-0634661, and ATM-06-42757.

[77] Zuyin Pu thanks Christos Haldoupis and another reviewer for their assistance in evaluating this paper.

\section{References}

Adachi, T., H. Fukunishi, Y. Takahashi, and M. Sato (2004), Roles of the EMP and QE field in the generation of columniform sprites, Geophys. Res. Lett., 31, L04107, doi:10.1029/2003GL019081.

Adachi, T., et al. (2008), Electric fields and electron energies in sprites and temporal evolutions of lightning charge moment, J. Phys. D, 41, 234010 , doi:10.1088/0022-3727/41/23/234010.

Adams, C. D. D., and R. L. Dowden (1990), VLF group delay of lightninginduced electron precipitation echoes from measurement of phase and amplitude perturbations at two frequencies, J. Geophys. Res., 95(A3), 2457-2462.

Armstrong, W. C. (1983), Recent advances from studies of the Trimpi effect, Antarct. J. U. S., 18, 281-283.

Asano, T., T. Suzuki, Y. Hiraki, E. Mareev, M. G. Cho, and M. Hayakawa (2009), Computer simulations on sprite initiation for realistic lightning models with higher-frequency surges, J. Geophys. Res., 114, A02310, doi:10.1029/2008JA013651.

Bain, W. C., and E. Hammond (1975), Ionospheric solar flare effect observations, J. Atmos. Terr. Phys., 37(3), 573-574.

Barr, R., D. Llanwyn Jones, and C. J. Rodger (2000), ELF and VLF radio waves, Jr. Atmos. Sol. Terr. Phys., 62, 1689-1718.

Barrington-Leigh, C. P., U. S. Inan, M. Stanley, and S. A. Cummer (1999), Sprites triggered by negative lightning discharges, Geophys. Res. Lett., 26(24), 3605-3608

Barrington-Leigh, C. P., U. S. Inan, and M. Stanley (2001), Identification of sprite and elves with intensified video and broadband array photometry, J. Geophys. Res., 106(A2), 1741-1750.

Bell, T. F., V. P. Pasko, and U. S. Inan (1995), Runaway electrons as a source of red sprites in the mesosphere, Geophys. Res. Lett., 22(16), 2127-2130.

Bell, T. F., S. C. Reising, and U. S. Inan (1998), Intense continuing currents following positive cloud-to-ground lightning associated with red sprites, Geophys. Res. Lett., 25(8), 1285-1288.

Belrose, J. S., and L. Thomas (1968), Ionization changes in the middle latitude D region associated with geomagnetic storms, J. Atmos. Terr. Phys., 30, 1397-1400.

Besser, B. P. (2007), Synopsis of the historical development of Schumann resonances, Radio Sci., 42, RS2S02, doi:10.1029/2006RS003495.

Blake, J. B., U. S. Inan, M. Walt, T. F. Bell, J. Bortnik, D. L. Chenette, and H. J. Christian (2001), Lightning-induced energetic electron flux enhancements in the drift loss cone, J. Geophys. Res., 106(A12), $29,733-29,744$.
Blecki, J., M. Parrot, and R. Wronowski (2009), ELF and VLF signatures of sprites registered onboard the low altitude satellite DEMETER, Ann. Geophys., 27, 2599-2605.

Boccippio, D. J., E. R. Williams, S. J. Heckman, W. A. Lyons, I. T. Baker, and R. Boldi (1995), Sprites, ELF transients, and positive ground strokes, Science, 269, 1088-1091.

Boeck, W. L., O. H. Vaughan, R. Blakeslee, B. Vonnegut, and M. Brook (1992), Lightning induced brightening in the airglow layer, Geophys. Res. Lett., 19, 99-102.

Bortnik, J., U. S. Inan, and T. F. Bell (2003), Energy distribution and lifetime of magnetospherically reflecting whistlers in the plasmasphere, J. Geophys. Res., 108(A5), 1199, doi:10.1029/2002JA009316.

Bortnik, J., U. S. Inan, and T. F. Bell (2006a), Temporal signatures of radiation belt electron precipitation induced by lightning generated MR whistler waves: 1. Methodology, J. Geophys. Res., 111, A02204, doi:10.1029/2005JA011182.

Bortnik, J., U. S. Inan, and T. F. Bell (2006b), Temporal signatures of radiation belt electron precipitation induced by lightning-generated MR whistler waves: 2. Global signatures, J. Geophys. Res., 111, A02205, doi:10.1029/2005JA011398.

Bösinger, T. A. Mika, S. L. Shalimov, C. Haldoupis, and T. Neubert (2006), Is there a unique signature in the ULF response to sprite-associated lightning flashes?, J. Geophys. Res., 111, A10310, doi:10.1029/ 2006JA011887.

Bracewell, R. N., K. G. Budden, J. A. Ratcliffe, J. W. Straker, and K. Weekes (1951), The ionosphere propagation of low- and very lowfrequency radio waves over distances less than $1,000 \mathrm{~km}$, Proc. Inst. Electr. Eng., Part 3, 98, 221.

Brown, R. T. (1973), Ionospheric effects of cosmic $\gamma$-ray bursts, Nature, 246, 83-84.

Burgess, W. C., and U. S. Inan (1990), Simultaneous disturbance of conjugate ionospheric regions in association with individual lightning flashes, Geophys. Res. Lett., 17(3), 259-262.

Burgess, W. C., and U. S. Inan (1993), The role of ducted whistlers in the precipitation loss and equilibrium flux of radiation belt electrons, J. Geophys. Res., 98(A9), 15,643-15,665.

Burke, C. P., and D. L. Jones (1996), On the polarity and continuing currents in unusually large lightning flashes deduced from ELF events, J. Atmos. Terr. Phys., 58(5), 531-540.

Carlson, B. E., N. G. Lehtinen, and U. S. Inan (2009), Terrestrial gamma ray flash production by lightning current pulses, J. Geophys. Res., 114 A00E08, doi:10.1029/2009JA014531.

Carpenter, D. L., U. S. Inan, M. L. Trimpi, R. A. Helliwell, and J. P. Katsufrakis (1984), Perturbations of subionospheric LF and MF signals due to whistler-induced electron precipitation bursts, J. Geophys. Res., 89(A11), 9857-9862.

Carpenter, D. L., U. S. Inan, E. W. Paschal, and A. J. Smith (1985), A new method for studying burst precipitation near the plasmapause, J. Geophys. Res., 90(A5), 4383-4388.

Chen, A. B., et al. (2008), Global distributions and occurrence rates of transient luminous events, J. Geophys. Res., 113, A08306, doi:10.1029/ 2008JA013101.

Chen, J. T., U. S. Inan, and T. F. Bell (1996), VLF strip holographic imaging of lightning-associated ionospheric disturbances, Radio Sci., 31(2), 335-348.

Cheng, Z., and S. A. Cummer (2005), Broadband VLF measurements of lightning-induced ionospheric perturbations, Geophys. Res. Lett., 32, L08804, doi:10.1029/2004GL022187.

Cheng, Z., S. A. Cummer, H.-T. Su, and R.-R. Hsu (2007), Broadband very low frequency measurement of $D$ region ionospheric perturbations caused by lightning electromagnetic pulses, J. Geophys. Res., 112, A06318, doi:10.1029/2006JA011840.

Chern, J. L., R. R. Hsu, H. T. Su, S. B. Mende, H. Fukunishi, Y. Takahashi, and L. C. Lee (2003), Global survey of upper atmospheric transient luminous events on the ROCSAT-2 satellite, J. Atmos. Sol. Terr. Phys., 65(5), 647-659.

Cho, M., and M. Rycroft (1998), Computer simulation of the electric field structure and optical emission from cloud-top to the ionosphere, J. Atmos. Sol. Terr. Phys., 60, 871-888.

Cho, M., and M. J. Rycroft (2001), Non-uniform ionisation of the upper atmosphere due to the electromagnetic pulse from a horizontal lightning discharge, J. Atmos. Sol. Terr. Phys., 63, 559-580.

Christian, H. J., et al. (2003), Global frequency and distribution of lightning as observed from space by the Optical Transient Detector, J. Geophys. Res., 108(D1), 4005, doi:10.1029/2002JD002347.

Clilverd, M. A., D. Nunn, S. J. Lev-Tov, U. S. Inan, R. L. Dowden, C. J. Rodger, and A. J. Smith (2002), Determining the size of lightninginduced electron precipitation pathes, J. Geophys. Res., 107(A8), 1168, doi:10.1029/2001JA000301. 
Clilverd, M. A., C. J. Rodger, and D. Nunn (2004), Radiation belt electron precipitation fluxes associated with lightning, J. Geophys. Res., 109 A12208, doi:10.1029/2004JA010644.

Cohen, M. B., U. S. Inan, and G. J. Fishman (2006), Terrestrial gamma ray flashes observed aboard Compton Gamma Ray Observatory/Burst and Transient Source Experiment and ELF/VLF radio atmospherics, J. Geophys. Res., 111, D24109, doi:10.1029/2005JD006987.

Cohen, M. B., U. S. Inan, and E. W. Paschal (2010), Sensitive broadband ELF/VLF radio reception with the AWESOME instrument, IEEE Trans. Geosci. Remote Sens., 48(1), 3-17, doi:10.1109/TGRS.2009.2028334.

Cotts, B. R. T., and U. S. Inan (2007), VLF observation of long ionospheric recovery events, Geophys. Res. Lett., 34, L14809, doi:10.1029/ 2007GL030094.

Cummer, S. A. (2003), Current moment in sprite-producing lightning, J. Atmos. Sol. Terr. Phys., 65, 499-508.

Cummer, S. A., and M. Füllekrug (2001), Unusually intense continuing current in lightning causes delayed mesospheric breakdown, Geophys. Res. Lett., 28, 495-498.

Cummer, S. A., and U. S. Inan (1997), Measurement of charge transfer in sprite-producing lightning using ELF radio atmospherics, Geophys. Res. Lett., 24, 1731-1734.

Cummer, S. A., and U. S. Inan (2000), Modeling ELF radio atmospheric propagation and extracting lightning currents from ELF observations, Radio Sci., 35(2), 385-394.

Cummer, S. A., and W. A. Lyons (2005), Implications of lightning charge moment changes for sprite initiation, J. Geophys. Res., 110, A04304, doi:10.1029/2004JA010812.

Cummer, S. A., and M. Stanley (1999), Submillisecond resolution lightning currents and sprite development: Observations and implications, Geophys. Res. Lett., 26(20), 3205-3208.

Cummer, S. A., U. S. Inan, T. F. Bell, and C. P. Barrington-Leigh (1998), ELF radiation produced by electrical currents in sprites, Geophys. Res. Lett., 25(8), 1281-1284.

Cummer, S. A., Y. Zhai, W. Hu, D. M. Smith, L. I. Lopez, and M. A. Stanley (2005), Measurements and implications of the relationship between lightning and terrestrial gamma ray flashes, Geophys. Res. Lett., 32, L08811, doi:10.1029/2005GL022778.

Cummer, S. A., H. U. Frey, S. B. Mende, R.-R. Hsu, H.-T. Su, A. B. Chen, H. Fukunishi, and Y. Takahashi (2006a), Simultaneous radio and satellite optical measurements of high-altitude sprite current and lightning continuing current, J. Geophys. Res., 111, A10315, doi:10.1029/ 2006JA011809.

Cummer, S. A., N. Jaugey, J. Li, W. A. Lyons, T. E. Nelson, and E. A. Gerken (2006b), Submillisecond imaging of sprite development and structure, Geophys. Res. Lett., 33, L04104, doi:10.1029/2005GL024969.

Doolittle, J. H., and D. L. Carpenter (1983), Photometric evidence of electron precipitation induced by first hop whistlers, Geophys. Res. Lett., 10(8), 611-614.

Dowden, R. L., and C. D. D. Adams (1988), Phase and amplitude perturbations on subionospheric signals explained in terms of echoes from lightning-induced electron precipitation ionization patches, J. Geophys. Res., 93, 11,543-15,550.

Dowden, R. L., and C. D. D. Adams (1989), Phase and amplitude perturbations on the NWC signal at Dunedin from lightning-induced electron precipitation, J. Geophys. Res., 94, 497-503.

Dowden, R. L., and C. D. D. Adams (1990), Location of lightning-induced electron precipitation from measurement of VLF phase and amplitude perturbations on spaced antennas and on two frequencies, J. Geophys. Res., 95(A4), 4135-4145.

Dowden, R. L., and C. D. D. Adams (1993), Size and location of lightninginduced ionisation enhancements from measurement of VLF phase and amplitude perturbations on multiple antennas, J. Atmos. Terr. Phys., $55,1335-1359$

Dowden, R. L., C. D. D. Adams, J. B. Brundell, and P. E. Dowden (1994), Rapid onset, rapid decay (RORD), phase and amplitude perturbations of VLF subionospheric transmissions, J. Atmos. Terr. Phys., 56(11), $1513-1527$.

Dowden, R. L., J. B. Brundell, and W. A. Lyons (1996a), Are VLF rapid onset, rapid decay perturbations produced by scattering off sprite plasma?, J. Geophys. Res., 101(D14), 19,175-19,183.

Dowden, R. L., J. B. Brundell, W. A. Lyons, and T. E. Nelson (1996b), Detection and location of red sprites by VLF scattering of subionospheric transmissions, Geophys. Res. Lett., 23(14), 1737-1740.

Dowden, R. L., J. B. Brundell, and C. J. Rodger (1997), Temporal evolution of very strong Trimpis observed at Darwin, Australia, Geophys. Res. Lett., 24, 2419-2422, doi:10.1029/97GL02357.

Edgar, B. C. (1976), The upper and lower frequency cutoffs of magnetospherically reflected whistlers, J. Geophys. Res., 81, 205-211.
Farges, T., E. Blanc, A. Le Pichon, T. Neubert, and T. H. Allin (2005), Identification of infrasound produced by sprites during the Sprite2003 campaign, Geophys. Res. Lett., 32, L01813, doi:10.1029/2004GL021212. Ferguson, J. A., and F. P. Snyder (1987), The segmented waveguide program for long wavelength propagation calculations, Tech. Rep. 1071, Naval Ocean Syst. Cent., San Diego, Calif.

Fishman, G. J., and U. S. Inan (1988), Observation of an ionospheric disturbance caused by a gamma-ray burst, Nature, 331, 418-420.

Fishman, G. J., et al. (1994), Discovery of intense gamma-ray flashes of atmospheric origin, Science, 264, 1313-1316.

Franz, R. C., R. J. Nemzek, and J. R. Winckler (1990), Television image of a large upward electrical discharge above a thunderstorm system, Science, 249, 48-51.

Fukunishi, H., Y. Takahashi, M. Kubota, K. Sakanoi, U. S. Inan, and W. A. Lyons (1996), Elves: Lightning-induced transient luminous events in the lower ionosphere, Geophys. Res. Lett., 23, 2157-2160, doi:10.1029/ 96GL01979.

Füllekrug, M., and C. Constable (2000), Global triangulation of intense lightning discharges, Geophys. Res. Lett., 27(3), 333-336.

Füllekrug, M., and S. Reising (1998), Excitation of Earth-ionosphere cavity resonances by sprite-associated lightning flashes, Geophys. Res. Lett., 25(22), 4145-4148.

Gerken, E. A., U. S. Inan, and C. P. Barrinton-Leigh (2000), Telescopic imaging of sprites, Geophys. Res. Lett., 27(17), 2637-2640.

Goldberg, R. A., J. R. Barcus, L. C. Hale, and S. A. Curtis (1986), Direct observation of magnetospheric electron precipitation stimulated by lightning, J. Atmos. Terr. Phys., 48(3), 293-299.

Greenberg, E., C. Price, Y. Yair, C. Haldoupis, O. Chanrion, and T. Neubert (2009), ELF/VLF signatures of sprite-producing lightning discharges observed during the 2005 EuroSprite campaign, J. Atmos. Sol. Terr. Phys., $71,1254-1266$

Grefenstette, B. W., D. M. Smith, B. J. Hazelton, and L. I. Lopez (2009) First RHESSI terrestrial gamma ray flash catalog, J. Geophys. Res., 114, A02314, doi:10.1029/2008JA013721.

Greifinger, C., and P. Greifinger (1979), On the ionospheric parameters which govern high-latitude ELF propagation in the Earth-ionosphere waveguide, Radio Sci., 14(5), 889-895.

Haldoupis, C., T. Neubert, U. S. Inan, A. Mika, T. H. Allin, and R. A. Marshall (2004), Subionospheric early VLF signal perturbations observed in one-toone association with sprites, J. Geophys. Res., 109, A10303, doi:10.1029/ 2004JA010651.

Haldoupis, C., R. J. Steiner, A. Mika, S. Shalimov, R. A. Marshall, U. S. Inan, T. Bosinger, and T. Neubert (2006), "Early/slow" events: A new category of VLF perturbations observed in relation with sprites, J. Geophys. Res., 111, A11321, doi:10.1029/2006JA011960.

Hardman, S. F., C. J. Rodger, R. L. Dowden, and J. B. Brundell (1998), Measurements of the VLF scattering pattern of the structured plasma of red sprites, IEEE Trans. Antennas Propag., 40, 29-38.

Hayakawa, M., T. Nakamura, Y. Hobara, and E. Williams (2004), Observation of sprites over the Sea of Japan and conditions for lightninginduced sprites in winter, J. Geophys. Res., 109, A01312, doi:10.1029/ 2003JA009905.

Helliwell, R. A. (1965), Whistlers and Related Ionospheric Phenomena, Stanford Univ. Press, Stanford, Calif.

Helliwell, R. A., J. P. Katsufrakis, and M. Trimpi (1973), Whistler-induced amplitude perturbation in VLF propagation, J. Geophys. Res., 78(22), 4679-4688.

Helliwell, R. A., S. B. Mende, J. H. Doolittle, W. C. Armstrong, and D. L. Carpenter (1980), Correlations between $\lambda 4278$ optical emissions and VLF wave events observed at L 4 in the Antarctic, J. Geophys. Res. 85(A7), 3376-3386.

Hobara, Y., N. Iwasaki, T. Hayashida, M. Hayakawa, K. Ohta, and H. Fukunishi (2001), Interrelation between ELF transients and ionospheric disturbances in association with sprites and elves, Geophys. Res. Lett., 28, 935-938.

Hu, W., and S. A. Cummer (2006), An FDTD model for low and high altitude lightning-generated em fields, IEEE Trans. Antennas Propag., 54, 1513-1522.

Hu, W., S. A. Cummer, W. A. Lyons, and T. E. Nelson (2002), Lightning charge moment changes for the initiation of sprites, Geophys. Res. Lett., 29(8), 1279, doi:10.1029/2001GL014593.

Hu, W., S. A. Cummer, and W. A. Lyons (2007), Testing sprite initiation theory using lightning measurements and modeled EM fields, J. Geophys. Res., 112, D13115, doi:10.1029/2006JD007939.

Huang, E., E. Williams, R. Boldi, S. Heckman, W. Lyons, M. Taylor, T. Nelson, and C. Wong (1999), Criteria for sprites and elves based on Schumann resonance observations, J. Geophys. Res., 104(D14), $16,943-16,964$ 
Ignaccolo, M., T. Farges, A. Mika, T. H. Allin, O. Chanrion, E. Blanc, T. Neubert, A. C. Fraser-Smith, and M. Fllekrug (2006), The planetary rate of sprite events, Geophys. Res. Lett., 33, L11808, doi:10.1029/ 2005GL025502.

Inan, U. S. (1990), VLF heating of the lower ionosphere, Geophys. Res. Lett., 17(6), 729-732.

Inan, U. S., and T. F. Bell (1977), The plasmapause as a VLF wave guide, J. Geophys. Res., 82(19), 2818-2827.

Inan, U. S., and D. L. Carpenter (1986), On the correlation of whistlers and associated subionospheric VLF/LF perturbations, J. Geophys. Res., 91(A3), 3106-3116.

Inan, U. S., and D. L. Carpenter (1987), Lightning-induced electron precipitation events observed at $\mathrm{L}=2.4$ as phase and amplitude perturbations on subionospheric VLF signals, J. Geophys. Res., 92(A4), 3293-3303.

Inan, U. S., and N. G. Lehtinen (2005), Production of terrestrial gamma-ray flashes by an electromagnetic pulse from a lightning return stroke, Geophys. Res. Lett., 32, L19818, doi:10.1029/2005GL023702.

Inan, U. S., D. L. Carpenter, R. A. Helliwell, and J. P. Katsufrakis (1985), Subionospheric VLF/LF phase perturbations produced by lightningwhistler induced particle precipitation, J. Geophys. Res., 90(A8), 7457-7469.

Inan, U. S., W. C. Burgess, T. G. Wolf, and D. C. Shafer (1988a), Lightningassociated precipitation of $\mathrm{MeV}$ electron from the inner radiation belt, Geophys. Res. Lett., 15(2), 172-175.

Inan, U. S., D. C. Shafer, W. P. Yip, and R. E. Orville (1988b), Subionospheric VLF signatures of nighttime D region perturbations in the vicinity of lightning discharges, J. Geophys. Res., 93(A10), 11,455-11,472.

Inan, U. S., T. G. Wolf, and D. L. Carpenter (1988c), Geographic distribution of lightning induced electron precipitation observed as VLF/LF perturbation events, J. Geophys. Res., 93(A9), 9841-9853.

Inan, U. S., M. Walt, H. Voss, and W. Imhof (1989), Energy spectra and pitch angle distribution of lightning-induced electron precipitation: Analysis of an event observed on the S81-1 (SEEP) satellite, J. Geophys. Res., 94(A2), 1379-1401

Inan, U. S., T. F. Bell, and J. V. Rodriguez (1991), Heating and ionization of the lower ionosphere by lightning, Geophys. Res. Lett., 18(4), $705-708$.

Inan, U. S., T. F. Bell, V. P. Pasko, D. D. Sentman, E. M. Wescott, and W. A. Lyons (1995), VLF signatures of ionospheric disturbances associated with sprites, Geophys. Res. Lett., 22(24), 3461-3464.

Inan, U. S., V. P. Pasko, and T. F. Bell (1996a), Sustained heating of the ionosphere above thunderstorms as evidenced in "early/fast" VLF events, Geophys. Res. Lett., 23(10), 1067-1070.

Inan, U. S., S. C. Reising, G. J. Fishman, and J. M. Horack (1996b), On the association of terrestrial gamma-ray bursts with lightning and implications for sprites, Geophys. Res. Lett., 23(9), 1017-1020.

Inan, U. S., A. Slingeland, V. P. Pasko, and J. V. Rodriguez (1996c), VLF and LF signatures of mesospheric/lower ionospheric response to lightning discharges, J. Geophys. Res., 101(A3), 5219-5238.

Inan, U. S., C. P. Barrington-Leigh, S. Hansen, V. S. Glukhov, T. F. Bell, and R. Rairden (1997), Rapid lateral expansion of optical luminosity in lightning-induced ionospheric flashes referred to as 'elves,' Geophys. Res. Lett., 24(5), 583-586.

Inan, U. S., N. G. Lehtinen, S. J. Lev-Tov, M. P. Johnson, and T. F. Bell (1999), Ionization of the lower ionosphere by $\gamma$-rays from a magnetar: Detection of a low energy (3-10 keV) component, Geophys. Res. Lett., 26(22), 3357-3360.

Inan, U. S., M. B. Cohen, R. K. Said, D. M. Smith, and L. I. Lopez (2006), Terrestrial gamma ray flashes and lightning discharges, Geophys. Res. Lett., 33, L18802, doi:10.1029/2006GL027085.

Inan, U. S., M. Golkowski, M. K. Casey, R. C. Moore, W. Peter, P. Kulkarni, P. Kossey, and E. Kennedy (2007), Subionospheric VLF observations of transmitter-induced precipitation of inner radiation belt electrons, Geophys. Res. Lett., 34, L02106, doi:10.1029/2006GL028494.

Ishaq, M., and D. L. Jones (1977), Method of obtaining radiowave propagation parameters for the Earth-ionosphere duct at E.L.F., Electron. Lett., $13,254$.

Israelevich, P. L., Y. Yair, A. D. Devir, J. H. Joseph, Z. Levin, I. Mayo, M. Moalem, C. Price, B. Ziv, and A. Sternlieb (2004), Transient airglow enhancements observed from the space shuttle Columbia during the MEIDEX sprite campaign, Geophys. Res. Lett., 31, L06124, doi:10.1029/2003GL019110.

Jasna, D., U. S. Inan, and T. F. Bell (1992), Precipitation of suprathermal (100EV) electrons by oblique whistler waves, Geophys. Res. Lett., 19(16), 1639-1642.

Johnson, M. P., and U. S. Inan (2000), Sferic clusters associated with early/ fast VLF events, Geophys. Res. Lett., 27(9), 1391-1394.
Johnson, M. P., U. S. Inan, and D. S. Lauben (1999a), Subionospheric VLF signatures of oblique (nonducted) whister-induced precipitation, Geophys. Res. Lett., 26(23), 3569-3572.

Johnson, M. P., U. S. Inan, S. J. Lev-Tov, and T. F. Bell (1999b), Scattering pattern of lightning-induced ionospheric disturbances associated with early/fast VLF events, Geophys. Res. Lett., 26(15), 2363-2366.

Kelley, M. C., C. L. Siefring, R. F. Pfaff, P. M. Kintner, M. Larsen, R. Green, R. H. Holzworth, L. C. Hale, J. D. Mitchell, and D. Le Vine (1985), Electrical measurements in the atmosphere and ionosphere over an active thunderstorm: 1. Campaign overview and initial ionospheric results, J. Geophys. Res., 90, 9815-9823.

Kreplin, R. W., T. A. Chubb, and H. Freidman (1962), X-ray and Lymanalpha emission from the Sun as measured from the NRL SR-1 satellite J. Geophys. Res., 67(6), 2231-2253

Kuo, C.-L., et al. (2007), Modeling elves observed by FORMOSAT-2 satellite, J. Geophys. Res., 112, A11312, doi:10.1029/2007JA012407.

Lauben, D. S., U. S. Inan, and T. F. Bell (1999), Poleward-displaced electron precipitation from lightning-generated oblique whisters, Geophys. Res. Lett., 26(16), 2633-2636.

Lauben, D. S., U. S. Inan, and T. F. Bell (2001), Precipitation of radiation belt electrons induced by obliquely propagating lightning-generated whistlers, J. Geophys. Res., 106, 29,745-29,770.

Lauter, E. A., and R. Knuth (1967), Precipitation of high energy particles into the upper atmosphere at medium latitudes after magnetic storms, J. Atmos. Terr. Phys., 29, 411-417.

Lefeuvre, F., R. Marshall, J. L. Pinon, U. S. Inan, D. Lagoutte, M. Parrot, and J. J. Berthelier (2009), On remote sensing of transient luminous events' parent lightning discharges by ELF/VLF wave measurements on board a satellite, J. Geophys. Res., 114, A09303, doi:10.1029/ 2009JA014154.

Lehtinen, N. G., and U. S. Inan (2007), Possible persistent ionization caused by giant blue jets, Geophys. Res. Lett., 34, L08804 doi:10.1029/2006GL029051.

Lev-Tov, S. J., U. S. Inan, and T. F. Bell (1995), Altitude profiles of localized D region density disturbances produced in lightning-induced electron precipitation events, J. Geophys. Res., 100(A11), 21,375-21,383.

Li, J., S. A. Cummer, W. A. Lyons, and T. E. Nelson (2008), Coordinated analysis of delayed sprites with high-speed images and remote electromagnetic fields, J. Geophys. Res., 113, D20206, doi:10.1029/ 2008JD010008.

Lohrey, B., and A. B. Kaiser (1979), Whistler-induced anomalies in VLF propagation, J. Geophys. Res., 84(A9), 5121-5130.

Lu, G. (2006), Transient electric field at high altitudes due to lightning: Possible role of induction field in the formation of elves, J. Geophys. Res., 111, D02103, doi:10.1029/2005JD005781.

Luque, A., and U. Ebert (2009), Emergence of sprite streamers from screening-ionization waves in the lower ionosphere, Nat. Geosci., 2, 757-760.

Marshall, R. A., and U. S. Inan (2005), High-speed telescopic imaging of sprites, Geophys. Res. Lett., 32, L05804, doi:10.1029/2004GL021988.

Marshall, R. A., and U. S. Inan (2006), High-speed measurements of smallscale features in sprites: Sizes and lifetimes, Radio Sci., 41, RS6S43, doi:10.1029/2005RS003353.

Marshall, R. A., and U. S. Inan (2010), Two-dimensional frequencydomain modeling of lightning EMP-induced perturbations to VLF transmitter signals, J. Geophys. Res., 115, A00E29, doi:10.1029/2009JA014761.

Marshall, R. A., U. S. Inan, and W. A. Lyons (2006), On the association of early/fast very low frequency perturbations with sprites and rare examples of VLF backscatter, J. Geophys. Res., 111, D19108, doi:10.1029/ 2006JD007219.

Marshall, R. A., U. S. Inan, and W. A. Lyons (2007), Very low frequency sferic bursts, sprites, and their association with lightning activity, J. Geophys. Res., 112, D22105, doi:10.1029/2007JD008857.

Marshall, R. A., U. S. Inan, and T. W. Chevalier (2008a), Early VLF perturbations caused by lightning EMP-driven dissociative attachment, Geophys. Res. Lett., 35, L21807, doi:10.1029/2008GL035358.

Marshall, R. A., R. T. Newsome, and U. S. Inan (2008b), Fast photometric imaging using orthogonal linear arrays, IEEE Trans. Geosci. Remote Sens., 46(11), 3885-3893.

Marshall, R. A., U. S. Inan, and V. S. Glukhov (2010), Elves and associated electron density changes due to cloud-to-ground and in-cloud lightning discharges, J. Geophys. Res., 115, A00E17, doi:10.1029/ 2009JA014469.

Mende, S. B., H. U. Frey, R. R. Hsu, H. T. Su, A. B. Chen, L. C. Lee, D. D. Sentman, Y. Takahashi, and H. Fukunishi (2005), D region ionization by lightning-induced electromagnetic pulses, J. Geophys. Res., 110, A11312, doi:10.1029/2005JA011064. 
Meng, C. (1976), Simultaneous observations of low-energy electron precipitation and optical auroral arcs in the evening sector by the DMSP 32 satellite, J. Geophys. Res., 81, 2771-2785.

Mika, A., and C. Haldoupis (2008), VLF studies during TLE occurrences in Europe: A summary of new findings, Space Sci. Rev., 137(1-4), 489-510.

Mika, A., C. Haldoupis, T. Neubert, R. R. Su, H. T. Hsu, R. J. Steiner, and R. A. Marshall (2006), Early VLF perturbations observed in association with elves, Ann. Geophys., 24, 2179-2189.

Mitra, A. P. (1974), Ionospheric Effects of Solar Flares, Springer, New York.

Moore, R. C., C. P. Barrington-Leigh, U. S. Inan, and T. F. Bell (2003), Early/fast VLF events produced by electron density changes associated with sprite halos, J. Geophys. Res., 108(A10), 1363, doi:10.1029/ 2002JA009816.

Moudry, D., H. Stenbaek-Nielsen, D. Sentman, and E. Wescott (2003), Imaging of elves, halos and sprite initiation at $1 \mathrm{~ms}$ time resolution, J. Atmos. Sol. Terr. Phys., 65, 509-518.

Mushtak, V. C., and E. R. Williams (2002), ELF propagation parameters for uniform models of the earth-ionosphere waveguide, J. Atmos. Sol. Terr. Phys., 64, 1989-2001.

Neubert, T., T. H. Allin, H. Stenbaek-Nielsen, and E. Blanc (2001), Sprites over Europe, Geophys. Res. Lett., 28(18), 3585-3588.

Neubert, T., et al. (2005), Co-ordinated observations of transient luminous events during the EuroSprite2003 campaign, J. Atmos. Sol. Terr. Phys. 67, 807-820, doi:10.1016/j.jastp.2005.02.004.

Neubert, T., et al. (2008), Recent results from studies of electric discharges in the mesosphere, Surv. Geophys., 29, 71-137.

Newsome, R. T., and U. S. Inan (2009), High-frame-rate reconstruction of a dynamic 2-D scene from continuous orthogonal projections, IEEE Trans. Geosci. Remote Sens., 47(8), 2646-2657.

Ohkubo, A., H. Fukunishi, Y. Takahashi, and T. Adachi (2005), VLF/ELF sferic evidence for in-cloud discharge activity producing sprites, Geophys. Res. Lett., 32, L04812, doi:10.1029/2004GL021943.

Pappert, R. A., and F. P. Snyder (1972), Some results of a mode-conversion program for VLF, Radio Sci., 7, 913-923.

Pasko, V. P. (1996), Dynamic coupling of quasi-electrostatic thundercloud fields to the mesosphere and lower ionosphere: sprites and jets, Ph.D. thesis, Stanford Univ., Stanford, Calif.

Pasko, V. P., and H. C. Stenbaek-Nielsen (2002), Diffuse and streamer regions of sprites, Geophys. Res. Lett., 29(10), 1440, doi:10.1029/ 2001GL014241.

Pasko, V. P., U. S. Inan, Y. N. Taranenko, and T. F. Bell (1995), Heating, ionization and upward discharges in the mesosphere due to intense quasielectrostatic thundercloud fields, Geophys. Res. Lett., 22(4), 363-368.

Pasko, V. P., U. S. Inan, T. F. Bell, and Y. N. Taranenko (1997), Sprites produced by quasi-electrostatic heating and ionization in the lower ionosphere, J. Geophys. Res., 102(A3), 4529-4561.

Pasko, V. P., U. S. Inan, and T. F. Bell (1998a), Ionospheric effects due to electrostatic thundercloud fields, J. Atmos. Sol. Terr. Phys., 60, 863-870.

Pasko, V. P., U. S. Inan, T. F. Bell, and S. C. Reising (1998b), Mechanism of ELF radiation from sprites, Geophys. Res. Lett., 25(18), 3493-3496.

Peter, W. B. (2007), Quantitative measurement of lightning-induced electron precipitation using VLF remote sensing, Ph.D. thesis, Stanford Univ., Stanford, Calif.

Peter, W. B., and U. S. Inan (2004), On the occurrence and spatial extent of electron precipitation induced by oblique nonducted whistler waves, J. Geophys. Res., 109, A12215, doi:10.1029/2004JA010412.

Peter, W. B., and U. S. Inan (2005), Electron precipitation events driven by lightning in hurricanes, J. Geophys. Res., 110, A05305, doi:10.1029/ 2004JA010899.

Peter, W. B., and U. S. Inan (2007), A quantitative comparison of lightninginduced electron precipitation and VLF signal perturbations, J. Geophys Res., 112, A12212, doi:10.1029/2006JA012165.

Potemra, T. A., and T. J. Rosenberg (1973), VLF propagation disturbances and electron precipitation at mid-latitudes, J. Geophys. Res., 78(10), $1572-1580$.

Poulsen, W. L., T. F. Bell, and U. S. Inan (1993a), The scattering of VLF waves by localized ionospheric disturbances produced by lightninginduced electron precipitation, J. Geophys. Res., 98(A9), 15,553-15,559.

Poulsen, W. L., U. S. Inan, and T. F. Bell (1993b), A multiple-mode threedimensional model of VLF propagation in the Earth-ionosphere waveguide in the presence of localized $D$ region disturbances, J. Geophys. Res., 98(A2), 1705-1717.

Price, C., M. Asfur, W. Lyons, and T. Nelson (2002), An improved ELF/ VLF method for globally geolocating sprite-producing lightning, Geophys. Res. Lett., 29(3), 1031, doi:10.1029/2001GL013519.

Price, C., et al. (2004), Ground-based detection of TLE-producing intense lightning during the MEIDEX mission on board the space shuttle Columbia, Geophys. Res. Lett., 31, L20107, doi:10.1029/2004GL020711.
Rakov, V. A., and M. A. Uman (2003), Lightning: Physics and Effects, Cambridge Univ. Press, Cambridge, U. K.

Rees, M. H. (1992), Auroral energy deposition rate, Planet. Space Sci., 40(2/3), 299-313.

Reising, S. C., U. S. Inan, and T. F. Bell (1996), Evidence for continuing current in sprite-producing cloud-to-ground lightning, Geophys. Res. Lett., 23(24), 3639-3642.

Rodger, C. J. (1999), Red sprites, upward lightning and VLF perturbations, Rev. Geophys., 37(3), 317-336.

Rodger, C. J. (2003), Subionospheric VLF perturbations associated with lightning discharges, J. Atmos. Sol. Terr. Phys., 65(5), 591-606.

Rodger, C. J., and D. Nunn (1999), VLF scattering from red sprites: Application of numerical modeling, Radio Sci., 34(4), 923-932.

Rodger, C. J., J. R. Wait, and R. L. Dowden (1997), Electromagnetic scattering from a group of thin conducting cyclinders, Radio Sci., 32(3), 907-912.

Rodger, C. J., J. R. Wait, and R. L. Dowden (1998), Scattering of VLF from an experimentally described sprite, J. Atmos. Sol. Terr. Phys., 60, 765-769.

Rodger, C. J., M. Cho, M. A. Cliverd, and M. J. Rycroft (2001), Lower ionospheric modification by lightning-EMP: Simulation of the night ionosphere over the United States, Geophys. Res. Lett., 28(2), 199-202.

Rodger, C. J., M. A. Clilverd, N. R. Thomson, D. Nunn, and J. Lichtenberger (2005), Lightning driven inner radiation belt energy deposition into the atmosphere: Regional and global estimates, Ann. Geophys., 23, 34193430 .

Rodriguez, J., U. S. Inan, and T. F. Bell (1994), Heating of the nighttime $D$ region by very low frequency transmitters, J. Geophys. Res., 99(A12), 23,329-23,338.

Ross, M., S. A. Cummer, T. K. Nielsen, and Y. Zhang (2008), Simultaneous remote electric and magnetic field measurements of lightning continuing currents, J. Geophys. Res., 113, D20125, doi:10.1029/ 2008JD010294

Rycroft, M. J. (1973), Enhanced energetic electron intensities at $100 \mathrm{~km}$ altitude and a whistler propagating through the plasmasphere, Planet. Space. Sci., 21(2), 239-251.

Sato, M., and H. Fukunishi (2003), Global sprite occurrence locations and rates derived from triangulation of transient Schumann resonance events, Geophys. Res. Lett., 30(16), 1859, doi:10.1029/2003GL017291.

Sato, M., Y. Takahashi, A. Yoshida, and T. Adachi (2008), Global distribution of intense lightning discharges and their seasonal variations, J. Phys. D, 41, 234011, doi:10.1088/0022-3727/41/23/234011.

Sechrist, C. F., Jr. (1974), Comparison of techniques for measurement of the D-region electron densities, Radio Sci., 9, 137-149.

Sentman, D. D. (1990), Approximate Schumann resonance parameters for a 2-scale-height ionosphere, J. Atmos. Terr. Phys., 52(1), 35-46.

Shao, X. M., and P. R. Krehbiel (1996), The spatial and temporal development of intracloud lightning, J. Geophys. Res., 101(D21), 26,641-26,668.

Simpson, J. J., and A. Taflove (2004), Three-dimensional FDTD modeling of impulsive ELF propagation about the earth-sphere, IEEE Trans. Antennas Propag., 52, 443-451.

Smith, D. M., L. I. Lopez, R. P. Lin, and C. P. Barrington-Leigh (2005), Terrestrial gamma-ray flashes observed up to $20 \mathrm{MeV}$, Science, 307(5712), 1085-1088.

Smith, R. L., and J. J. Angerami (1968), Magnetospheric properties deduced from OGO 1 observations of ducted and nonducted whistlers, J. Geophys. Res., 73(1), 1-20.

Stanley, M. A. (2000), Sprites and their parent discharges, Ph.D. thesis, N. M. Inst. of Min. and Technol., Socorro.

Stanley, M., P. Krehbiel, M. Brook, C. Moore, W. Rison, and B. Abrahams (1999), High speed video of initial sprite development, Geophys. Res. Lett., 26(20), 3201-3204.

Stanley, M. A., X.-M. Shao, D. M. Smith, L. I. Lopez, M. B. Pongratz, J. D. Harlin, M. Stock, and A. Regan (2006), A link between terrestrial gamma-ray flashes and intracloud lightning discharges, Geophys. Res. Lett., 33, L06803, doi:10.1029/2005GL025537.

Su, H. T., A. B. Hsu, R. R. Chen, Y. C. Wang, W. S. Hsiao, W. C. Lai, L. C. Lee, M. Sato, and H. Fukunishi (2003), Gigantic jets between a thundercloud and the ionosphere, Nature, 423, 974-976.

Taranenko, Y. N., and R. Roussel-Dupre (1996), High altitude discharges and gamma-ray flashes: A manifestation of runaway air breakdown, Geophys. Res. Lett., 23(5), 571-574.

Taranenko, Y. N., U. S. Inan, and T. F. Bell (1992), Optical signatures of lightning-induced heating of the D region, Geophys. Res. Lett., 19(18), $1815-1818$

Taranenko, Y. N., U. S. Inan, and T. F. Bell (1993a), The interaction with the lower ionosphere of electromagnetic pulses from lightning: Heating, attachment, and ionization, Geophys. Res. Lett., 20(15), 1539-1542. 
Taranenko, Y. N., U. S. Inan, and T. F. Bell (1993b), The interaction with the lower ionosphere of electromagnetic pulses from lightning: Excitation of optical emissions, Geophys. Res. Lett., 20(23), 2675-2678.

Taylor, M. J., et al. (2008), Rare measurements of a sprite with halo event driven by a negative lightning discharge over Argentina, Geophys. Res. Lett., 35, L14812, doi:10.1029/2008GL033984.

Tellegen, B. D. H. (1933), Interaction between radio-waves?, Nature, 131, 840.

Thomas, J. N., R. H. Holzworth, M. P. McCarthy, and O. Pinto Jr. (2005), Predicting lightning-driven quasi-electrostatic fields at sprite altitudes using in situ measurements and a numerical model, Geophys. Res. Lett., 32, L10809, doi:10.1029/2005GL022693.

Thomson, N. R., C. J. Rodger, and M. A. Clilverd (2005), Large solar flares and their ionospheric D region enhancements, J. Geophys. Res., 110, A06306, doi:10.1029/2005JA011008.

van der Velde, O. A., A. Mika, S. Soula, C. Haldoupis, T. Neubert, and U. S. Inan (2006), Observations of the relationship between sprite morphology and in-cloud lightning processes, J. Geophys. Res., 111, D15203, doi:10.1029/2005JD006879.

Veronis, G., V. P. Pasko, and U. S. Inan (1999), Characteristics of mesospheric optical emissions produce by lightning discharges, J. Geophys. Res., 104(A6), 12,645-12,656.

Voss, H. D., W. L. Imhof, M. Walt, J. Mobilia, E. E. Gaines, J. B. Reagan, and U. S. Inan (1984), Lightning induced electron precipitation, Nature, $312,740-742$.
Voss, H. D., M. Walt, W. L. Imhof, J. Mobilia, and U. S. Inan (1998), Satellite observations of lightning-induced electron precipitation, J. Geophys. Res., 103, 11,725-11,744.

Williams, E., E. Downes, R. Boldi, W. Lyons, and S. Heckman (2007), Polarity asymmetry of sprite-producing lightning: A paradox?, Radio Sci., 42, RS2S17, doi:10.1029/2006RS003488.

Yair, Y., C. Price, M. Ganot, E. Greenberg, R. Yaniv, B. Ziv, Y. Sherez, A. Devir, J. Bór, and G. Sátori (2009), Optical observations of transient luminous events associated with winter thunderstorms near the coast of Israel, Atmos. Res., 91, 529-537.

Yang, H., and V. P. Pasko (2005), Three-dimensional finite difference time domain modeling of the Earth-ionosphere cavity resonances, Geophys. Res. Lett., 32, L03114, doi:10.1029/2004GL021343.

Yashunin, S. A., E. A. Mareev, and V. A. Rakov (2007), Are lightning M components capable of initiating sprites and sprite halos?, J. Geophys. Res., 112, D10109, doi:10.1029/2006JD007631.

Zabotin, N. A., and J. W. Wright (2001), Role of meteoric dust in sprite formation, Geophys. Res. Lett., 28(13), 2593-2596.

S. A. Cummer, Electrical and Computer Engineering Department, Duke University, CIEMAS 3455, Durham, NC 27708, USA.

U. S. Inan and R. A. Marshall, STAR Laboratory, Stanford University, 350 Serra Mall, Rm. 306, Stanford, CA 94305, USA. (inan@stanford. edu; robertm@bu.edu) 